The Singapore Economic Review, Vol. 65, No. 1 (2020) 161-192

(C) The Author(s)

DOI: $10.1142 / \mathrm{S} 021759081746002 \mathrm{X}$

\title{
STUDY ON CHINA'S ECONOMIC DEVELOPMENT FROM THE PERSPECTIVE OF STRONG SUSTAINABILITY
}

\author{
WANPING YANG* ${ }^{*}$ and JINKAI ZHAO \\ School of Economics and Finance \\ Xi'an Jiaotong University, Xi'an 710061, P. R. China \\ *wanpingyang@mail.xjtu.edu.cn \\ †jinkaizhao@stu.xjtu.edu.cn
}

Published Online 23 April 2018

\begin{abstract}
Theoretical researchers and policy makers have been using both traditional production factors and relatively new production factors to explain the different growth rates in different countries and regions. However, as pollution becomes more serious, the ecological environment gradually becomes an important part of the national (regional) development strategy. Few scholars have laid their hands on energy and environmental factors in the study of China's economic growth. On the contrary, they have frequently considered physical and human capital accumulation as the main sources of China's economic growth. Thus, strong sustainability should attract more attention from researchers. This article attempts to shed light on the sources of China's economy from the perspective of strong sustainability. Employing a Cobb-Douglas production function, this paper introduces environment pollution, as a key natural capital, and energy consumption into the economic accounting framework. We also introduce government intervention, financial structure, industrial structure and degree of openness into the framework of total factor productivity to examine the effectiveness of the Chinese government's direct and indirect participation in the markets. Then, we use the long-term growth accounting equation of China to decompose its economic growth and to analyze the decomposition results dynamically. In addition, this paper analyzes the short-term change of China's economic growth by using a VAR model. The results revealed three facts. First, we find an inverted U-shaped relationship between the degree of openness and the industrial structure and their marginal growth effects, a U-shaped relationship between the financial structure and its marginal growth effect and a negative relationship between the government intervention and gross domestic product growth. Secondly, China's economic development approach was still extensive and unsustainable, and it should follow a model that relies more on total factor productivity and relies less on ecological factors. China's economic growth mainly depended on physical capital and energy consumption, and environment pollution was also a necessary byproduct of economic growth, however, the contribution of human capital and total factor productivity were small. Last but not the least, in the short term, the total factor productivity was an important source of China's economic growth.
\end{abstract}

Keywords: Total factor productivity; economic growth; ecological loss; strong sustainability.

JEL Classification: C13, O11.

†Corresponding author.

This is an Open Access article published by World Scientific Publishing Company. It is distributed under the terms of the Creative Commons Attribution 4.0 (CC-BY) License. Further distribution of this work is permitted, provided the original work is properly cited. 


\section{Introduction}

Since China launched their market-oriented reform and opening-up policies in 1978, China's economic growth has been remarkable. What is China's source of economic growth? Is it efficiency, factor inputs or ecological loss? What are the main factors affecting the change of China's economic growth in short term? Many scholars have studied the Chinese economy. Some scholars believe that the key driving force behind China's economic miracle is the use of soaring inputs and that the contribution of productivity growth is limited. Chow showed that from 1952 to 1980 China's economic growth is mainly due to the accumulation of capital (Chow, 1993). Krugman argued that China would eventually face a limit on growth, since the economy heavily depends on a massive increase in input with only small improvements in productivity (Krugman, 1994). His view caused a wide range of international influence. Based on an analysis of Chow, Hu and Khan pointed out that capital accumulation is a major factor for China's economic growth from 1952 to 1994. China's TFP grows by about $4 \%$ from 1979 to 1994, and its contribution to China's economic growth is over 40\% (Hu and Khan, 1997). Chow and Liu used data from 1978 to 1998 to estimate the contribution of physical capital, labor and TFP on economic growth. They found that the contribution of physical capital is $66.34 \%$, whereas the contribution of labor and TFP is $5.7 \%$ and $27.59 \%$, respectively. (Chow and Liu, 2002). Young pointed out that the TFP growth rates in China are lower than $1.5 \%$, and their contribution to economic growth is less than $20 \%$, and he argued that China's main contributors to growth are the soaring increases in inputs, such as labor and capital (Young, 2003). Aoki identified five phases of economic development of China: $M$ (Malthusian), $G$ (government-led), $K$ (à la Kuznets), $H$ (human capital based) and PD (post demographic transition). The phases are common to Japan and Korea. In the different phases of economic development, China has different sources of growth (Aoki, 2011). Recently, Krugman argued that China is experiencing a plummeting investment-income trend, and no matter what the government does, investments will fall sharply, and dramatic spending will be required to take the place of investing. However, China's consumption growth is too slow, and it is not enough to avoid severe economic downturn (Krugman, 2013).

In addition to inputs factors, as the pollution situation becoming more serious, the ecological environment gradually becomes an important part of national (regional) development strategy whether in China or in other countries (regions). Studies mentioned above do not consider the role of ecological factors in China's economic growth. Some scholars try to study the relationship between economic growth and energy consumption or ecological environment in China. Naminse and co-workers investigated the relationship among energy consumption, carbon emissions and economic growth in China from 1952 to 2012 and conducted static and dynamic regression analysis on the determinants of carbon emissions and economic growth. They found that coal has a dominant impact on China's economic growth and carbon emissions, and gross domestic product (GDP) has a bi-directional relationship with carbon dioxide emissions, coal, gas and electricity consumption (Long et al., 2015). Jiang investigated the linkage between China's output growth and its pollution emissions. He found that the growth of total factor productivity 
from 1997 to 2011 is accompanied by increasing pollution emissions (Jiang, 2015). However, few scholars have laid their hands on energy and environmental factors in the study of China's economic growth. On the contrary, they have frequently paid attention to sources of China's economic growth by regarding just physical capital and labor as inputs factors. They slightly touched upon the area of studies on the energy inputs and environmental impacts, which diminish the relevance for assessing the true sustainability of China's growth mode.

With the raising concerns about energy and environmental issues, the sustainable theory came into being. According to whether natural capital and manmade capital can be completely replaced, Pearce et al. (1989) divided sustainable development into strong sustainability and weak sustainability. The weak sustainability holds that one capital can be substituted by other capitals (Pearce et al., 1989), that is to say, various type capitals are interchangeable. This means that more choices will be provided in sustainable economic development without caring about ecological limits. The weak sustainability just ensures that the general wealth is not reduced. This theory is favored by neo-classical economists and by policy-makers. Following the weak sustainability, higher economic growth has occurred at the expense of severe ecological degradation. In the past 30 years, China's remarkable economic achievements and the rapid deterioration of the ecological environment are examples. In fact, any economic development objectively exists the critical value of an ecological environment. To achieve economic growth, we must consider the ecological carrying capacity of its particular resources and environment. Thus, strong sustainability, which assumes that the general natural capital is partly replaced and the key natural capital could not be replaced (Pearce et al., 1989), should be integrating into the mainstream of China's policy development. Here are some China's concrete practices of strong sustainability. For instance, The Eighteenth National Congress added ecological civilization construction into the Party Constitution. In May 2015, the State Council issued opinions on speeding up the construction of ecological civilization. In December 2016, the general office of the State Council issued the measures for the evaluation and assessment of ecological civilization construction.

Strong sustainability acknowledges nature as a capital, which means that not only the fields of thought in ecological economics and environmental economics are expanded, but also some opinions in economics will be modified accordingly, such as the traditional economic accounting method. The natural resource, as a type of production factor, a scarce resource, will lose its existence by consumptive use, resulting in environmental costs or ecological costs caused by economic activities. The existing accounting method focusses only on the money consumed, not the value obtained, and it not only covers the destruction of the natural ecological environment, but also describes the destruction as economic benefits. Thus, from the perspective of strong sustainability, natural capital should be incorporated into an economic measurement system to represent true prices, costs and values. At this point, the net income of economic activities equals to the surplus that the total output value deducting production costs and ecological environment costs. However, because of the lack of environmental market pricing in reality, it is difficult to add the environmental costs into production costs. Therefore, in the study of the source of 
economic growth, there are usually two ways to deal with the environmental variable. One way is to introduce pollution discharge, as an undesired output, into the production function (Yuan and Ban, 2017; Zha and Li, 2017). The other is to treat the environment as a new input factor and introduce it into the production functions as an unpaid input (Tyteca, 1997; Tzouvelekas et al., 2006).

From the perspective of strong sustainability, this paper views environment as a natural capital and introduces it into a Cobb-Douglas production function. At the same time, the energy consumption is incorporated into the accounting framework to explore the source of China's economic growth. Now, China is influencing by the complicated international environment and the deep domestic economic contradictions. It enters a stage where growth is shifting, structure is adjusting and stimulus is digesting. The balance, coordination and sustainability of China's economic growth need strengthening. There is no doubt that China's economic development should turn to TFP driven. However, the dilemma of the transformation lies in the lagging construction of the system and the structural imbalance of the economy (Jin and Tao, 2015). The institutional mechanism is reflected in the government's behavior toward the market, and the economic structure involves the industrial structure, the financial structure and the degree of openness. Therefore, this paper also tries introducing government intervention, financial structure, industrial structure and degree of openness into the framework of total factor productivity to reflect the effectiveness of the Chinese government's direct and indirect participation in the market. We attempt to shed light on the sources of China's economic growth and its change. The results revealed: (1) the government intervention showed a simple negative relation to China's economy, and financial structure, industrial structure and degree of openness showed the complex non-linear relations to China's economy; (2) China's economic development approach was still extensive and unsustainable, and it should follow a model that relies more on total factor productivity and relies less on ecological factors; (3) the total factor productivity was an important source of economic growth change.

\section{Literature Review}

In the process of exploring the source of economic growth, the complex relations among resources, environment and economy are unavoidable. Under the framework of neoclassical growth model and endogenous growth model, scholars try to introduce resource constraints, energy constraints and environmental constraints into the economic growth model.

Nordhaus is the first to construct a new classical growth model considering resource factors (resources and land) based on Solow model. He defined "growth drag" which was caused by the limitation of the resource factors. Then, taking the United States as the sample, he worked out that the resistance of resource factors to American economic growth was 0.0024 (Nordhaus et al., 1992). Later, Romer further built a theory framework of growth drag accounting (Romer, 2001), which together with study of Nordhaus laid a theoretical and empirical foundation for energy and environmental constraints in the process of economic growth. Chung established a dynamic equilibrium model of energy 
and environment and studied carbon dioxide emissions control in Canada and the United States (Chung et al., 1997). Aghion et al. believed that among the analysis methods of optimal path of economic growth with resources and environmental factors, the Schumpeter method could divide capital into intellectual capital and physical capital. By this method, the technology could be internalized and the investment activities could be divided into two parts. The method can reveal what sustainability with unlimited growth in consumption could be guaranteed. Therefore, they adopted the connotation of sustainable development defined by Dasgupta and built a growth model considering environmental pollution and non-renewable resource constraints based on Schumpeter model (Dasgupta and David, 1994; Aghion et al., 1998). Sweeney and Klavers (2007) introduced energy, resources and environmental factors into Ramsey-Cass-Koopmans model and used the model to analyze the optimal inter-temporal mining path of non-renewable energy sources. Smulders and Bretschger argued that the reproduction of natural resources has the similar dynamic characteristics of capital accumulation. They established an environmental accumulation equation including environmental pollution and natural resources. Then, the economic system was divided into two parts by adding the traditional capital accumulation equation. Their analysis results showed that the natural resources, environmental pollution and physical capital accumulation would have the same growth rate, and the economic growth would continue to maintain in a long term (Smulders et al., 2010).

In the process of promoting economic growth, most of industrialized economies in the world have been plagued by excessive consumption of non-renewable resources and deterioration of ecological environment (Zhang, 2012). In 1970s, the pessimistic judgment of Rome club and the spread of sustainable development stimulated people's enthusiasm for economic growth and economic sustainable development. In the early study of Dasgupta and Heal and Solow, the non-renewable resources and environmental factors are put into neoclassical growth model to explore the long-term economic growth path. However, they pointed out that the sustained growth of per capita consumption is not necessarily limited by the limited natural resources (Solow, 1974; Dasgupta and Heal, 1979). Since 1990 s, in the context of widespread concern with global climate change and development of endogenous growth theory, Field (2005), Soytas and Ramazan (2003) and Grimaud and Rougé (2003) tried to introduce natural resources, energy and environmental factors into endogenous growth theory.

On the one hand, since the mid-1990s, the international community questioned the pattern of China's economic growth, such as China's economic threat (Zhang, 2012), and China's annual environmental losses account for about 8\% of GDP (World Bank, 1997). On the other hand, China's energy and environmental issues were highlighting. These two aspects greatly absorbed the attention of some scholars and experts to study the growth path of China's economy. Beginning with the studies of Managi and Kaneko (2006) and $\mathrm{Hu}$ et al. (2008), environmental factors are gradually incorporated into the analysis framework of China's economic growth. According to the differences of accounting methods, the relevant studies could be divided into three categories. The first one is based on the growth accounting method, and the representative studies include Hu et al. (2008), Chen (2010), Li and Huang (2015) and so on. The second one is based on the stochastic 
frontier function method, and the main studies include Xue and Liang (2011), Kuang and Peng (2012) and so on. The third one is TFP accounting and decomposition based on the data envelopment analysis, and the representative studies include Managi and Kaneko (2006), Michio and Tanaka (2007), Liu and An (2012), Chang et al. (2013), Zheng and Zhu (2013), Wu et al. (2015), Zha and Li (2017) and so on.

To sum up, some scholars and experts have drawn their eyes on studies of China's economic growth. However, they slightly touched upon the area of studies on the energy inputs and environmental impacts. This paper will explore the sources of China's economic growth from the perspective of strong sustainability, which will greatly broaden our insight into China's economy development.

\section{Research Method and Empirical Data}

\subsection{Research method}

In order to avoid the deficiency that the classical Cobb-Douglas production function only considers labor quantity, this paper considers both quantity and quality. In addition, we treat the environment as a key natural capital. The environment factor and energy consumption are also put into production function:

$$
Y=A K^{\alpha} L^{\beta} N^{\theta} P^{\varphi}
$$

where $Y$ represents the output, $A$ represents the total factor productivity, $K$ represents the physical capital, $L$ denotes the human capital, $N$ denotes the energy consumption and $P$ denotes the environment loss; $\alpha>0, \beta>0, \theta>0, \varphi>0$ represent elasticity of physical capital, human capital, energy consumption and environment loss.

Since Solow's seminal contribution, total factor productivity is widely used in economic growth accounting frameworks, and it becomes an important indicator for judging economic growth pattern. In China, a government-dominated country, government obviously participates in market. China's economic development should depend more on TFP, but its dilemma lies in the lagging construction of China's system and mechanism that mostly resulted from government. On the one hand, the system and mechanism are reflected in the government's direct participation in the market. On the other hand, the government performance indirectly affects the economic operation efficiency by adjusting the degree of openness, industrial structure and financial structure. Government intervention can affect China's economic productivity by participating in the resources allocation. The degree of openness, the industrial structure and the financial structure reflect China's economic structure. They relates to the coordinated development of various sectors in China. The openness reflects the economic link between China and the world. With the increase in degree of openness, China can introduce more foreign advanced technology and management experience. The introduction greatly narrows the gap between China and foreign countries. Industrial structure reflects the domestic industry development trend. A reasonable industrial structure not only relates to the coordinated development of China's economy, but also relates to the proper resources allocation in different industries. 
Therefore, the rational adjustment of industrial structure can improve the efficiency of resource use. The financial structure reflects the relationship between financial markets and macroeconomics. As the financial market affects the macroeconomic through investment and other means, a reasonable management of financial markets is conducive to economic growth. In order to reflect the effect of China's government on economy from both direct and indirect aspects, we add system and structure factors into TFP measuring. The system factor is measured by the degree of government intervention. The structure factor is a measurement of economic structure, and it includes degree of openness, industrial structure and financial structure.

According to the above analysis, we will quantify the total factor productivity:

$$
A=A_{0} e^{\left(\tau_{1} \text { ind }+\tau_{2} \text { ind }^{2}+\rho_{1} \text { fin }+\rho_{2} \text { fin }^{2}+\sigma_{1} \operatorname{gov}+\sigma_{2} \operatorname{gov}^{2}+\eta_{1} \text { open }+\eta_{2} \text { open }^{2}+\varepsilon\right)},
$$

where ind denotes industrial structure, fin denotes financial structure, gov denotes government intervention, open denotes degree of openness, $\varepsilon$ is the random disturbance term and $A_{0}$ is a constant term. In the quantization, we add square term of variables to test whether there is a non-linear relationship between the factors and total factor productivity and to capture the structural changes caused by the time-varying effect.

Substituting Equation (2) into Equation (1):

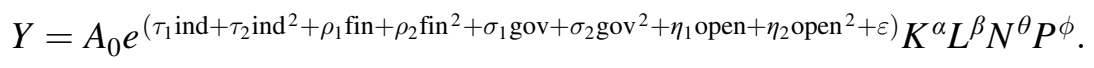

Taking logarithm on both sides of the equal (3), we get:

$$
\begin{aligned}
\ln Y= & C+\alpha \ln K+\beta \ln L+\theta \ln N+\phi \ln P+\tau_{1} \text { ind }+\tau_{2} \text { ind }^{2}+\rho_{1} \text { fin }+\rho_{2} \text { fin }^{2} \\
& +\sigma_{1} \text { gov }+\sigma_{2} \text { gov }^{2}+\eta_{1} \text { open }+\eta_{2} \text { open }^{2}+\varepsilon .
\end{aligned}
$$

Taking the derivative of Equation (4) with respect to time and using the difference instead of the differential, we obtain

$$
\begin{aligned}
\frac{\Delta Y_{t+1}}{Y_{t}}= & \alpha \frac{\Delta K_{t+1}}{K_{t}}+\beta \frac{\Delta L_{t+1}}{L_{t}}+\theta \frac{\Delta N_{t+1}}{N_{t}}+\phi \frac{\Delta P_{t+1}}{P_{t}}+\pi \Delta \operatorname{ind}_{t+1}+\lambda \Delta \text { fin }_{t+1} \\
& +\mu \Delta \operatorname{gov}_{t+1}+\omega \Delta \text { open }_{t+1},
\end{aligned}
$$

where $\Delta X_{t+1}=X_{t+1}-X_{t}, \pi=\tau_{1}+2 \tau_{2} \operatorname{ind}_{t}, \lambda=\rho_{1}+2 \rho_{2}$ fin $_{t}, \mu=\sigma_{1}+2 \sigma_{2} \operatorname{gov}_{t}, \omega=$ $\eta_{1}+2 \eta_{2}$ open $_{t}$

The above formula namely is

$$
g_{Y}=g_{A}+\alpha g_{K}+\beta g_{L}+\theta g_{N}+\varphi g_{p} .
$$

The $g$ represents the growth rate of corresponding variables. The economic meaning of formula (6) is that the growth rate of output is expressed as a linear summation of total factor productivity growth rate and input growth rates. Moreover, $g_{A}$ could be decomposed into variable weight summation of change of industrial structure, financial structure, government intervention and degree of openness:

$$
g_{A}=\pi \Delta \operatorname{ind}_{t+1}+\lambda \Delta \operatorname{fin}_{t+1}+\mu \Delta \operatorname{gov}_{t+1}+\omega \Delta \text { open }_{t+1} .
$$


In fact, Equation (7) describes the transmission mechanism of system factors and structure factors for the total factor productivity.

\subsection{Data description}

This paper utilizes China's time series data between 1981 and 2014. The data are derived from "China Statistical Yearbook", "China Industrial Economy Statistics" and the website of China Statistics Bureau. The variables are as follows:

(1) The physical capital: $K$. As China has no official statistical data of physical capital, related studies often estimate it. This paper also forms an estimation by perpetual inventory method. The basic estimating formula is

$$
K_{t}=I_{t}+\left(1-\delta_{t}\right) K_{t-1}
$$

where $K_{t}$ represents the physical capital stock in year $t, K_{t-1}$ represents the physical capital stock in year $t-1, I_{t}$ represents the net investment in year $t$ and $\delta_{t}$ represents the physical capital depreciation rate in year $t$. The formula (8) mainly involves selection of depreciation rate, determination of the physical capital stock in base year, selection of investment index and the construction of an investment price index. We selected $9.6 \%$ as the depreciation rate following Zhang et al. (2003) and used $10 \%$ of the fixed capital formation in 1978 as the base physical capital stock following Young (2003). Meanwhile, the fixed capital formations were treated as the net investment in each year. China did not disclose the price indices of investment in fixed assets before 1991. Thus, related studies often search for the corresponding index as the investment deflator. Following Zhang et al. (2003), we calculated the implicit deflator of investment from 1981 to 1991 based on the value of 1978, according to the fixed capital formation total price index provided by "Historical accounting data of China GDP (1952 to 2004)". The calculated index and the price index of investment in fixed assets provided by the "China Statistical Yearbook" from 1992 to 2014 were together as the time series of investment price index.

(2) The human capital: $L$. In order to consider the quantity and quality of labor input at the same time, the human capital was measured by the product of employment number and average schooling years of laboring population.

(3) The energy consumption: $N$. We utilized the total number of standard coal used in economic activities to represent energy consumption.

(4) The pollution index: $P$. In this paper, environment loss is estimated by method of our published paper. We selected emissions of industrial waste water and emissions of industrial waste gas (it included sulfur dioxide and smoke dust (powder), production of industrial solid waste, emission of $\mathrm{CO}_{2}$ ) and used an objective evaluation method (the longitudinal grade away method) to account pollution index (for details, see Appendix A). Yuan and Li (2013) adopted this method to study the dynamic change of China's ecological environment, and Liu and Yuan (2015) adopted this method to measure provincial environmental quality for China. 
Table 1. Summary Statistics

\begin{tabular}{lccccc}
\hline Variable & $\begin{array}{c}\text { Observed } \\
\text { Values }\end{array}$ & $\begin{array}{c}\text { Average } \\
\text { Value }\end{array}$ & $\begin{array}{c}\text { Standard } \\
\text { Deviation }\end{array}$ & $\begin{array}{c}\text { Minimum } \\
\text { Value }\end{array}$ & $\begin{array}{c}\text { Maximum } \\
\text { Value }\end{array}$ \\
\hline gdp & 34 & $33,236.02$ & $29,124.55$ & $4,450.79$ & $103,052.45$ \\
$K$ & 34 & $77,159.50$ & $82,210.56$ & $11,224.60$ & $30,518.90$ \\
$L$ & 34 & $449,743.28$ & $147,786.0$ & $205,726.13$ & $730,743.85$ \\
$N$ & 34 & $186,181.13$ & $117,529.22$ & $59,447.23$ & $426,000.20$ \\
$P$ & 34 & 3.44 & 2.06 & 1.79 & 8.67 \\
ind & 34 & 0.69 & 0.20 & 0.41 & 1.06 \\
open & 34 & 0.38 & 0.14 & 0.14 & 0.65 \\
fin & 34 & 0.77 & 0.22 & 0.53 & 1.29 \\
gov & 34 & 0.17 & 0.04 & 0.10 & 0.24 \\
\hline
\end{tabular}

(5) The output: gdp. GDP is used to measure the level of China's economy. We calculated real GDP of 1981-2014 based on the GDP of 1978.

(6) The industrial structure: ind. It was measured by the ratio of output value of tertiary industry to output value of second industrial.

(7) The degree of openness: open. It was measured by the ratio of total import and export to GDP.

(8) The financial structure: fin. Following Demirgüç-Kunt et al. (2011), this paper used ratio of size of a country's financial market (stock market and bond market) to the size of banking sector to measure financial structure.

(9) The government intervention: gov. The variable was measured by the proportion of government expenditure on GDP.

In Table 1, we report summary statistics for the variables used in the empirical analysis.

\section{The Long-Term Economic Growth of China}

\subsection{Regression analysis}

Before regression, we use the augmented Dickey-Fuller (ADF) method to test the stability of variables. The null hypothesis is generally defined as the presence of a unit root and the alternative hypothesis is either stationary. However, the test results depend on the type of test used. According to Figure 1, all the time series show a clear trend, so both trend and intercept are included in test equation when using the ADF test. The specific results are shown in Table 2. The ADF tests indicate that the time series of all variables are nonstationary and all of them are integrated of orders one. Thus, we can conduct the cointegration analysis. In this paper, all the analyses of data are by EViews7 software.

In order to examine changes in the regression coefficients, we utilize stepwise regression method. The regression results are shown in Table 3.

In the process of regression, we find that quadratic term of government intervention is not significant, and the RSS with the quadratic term not obviously decreases compared to 
170 The Singapore Economic Review
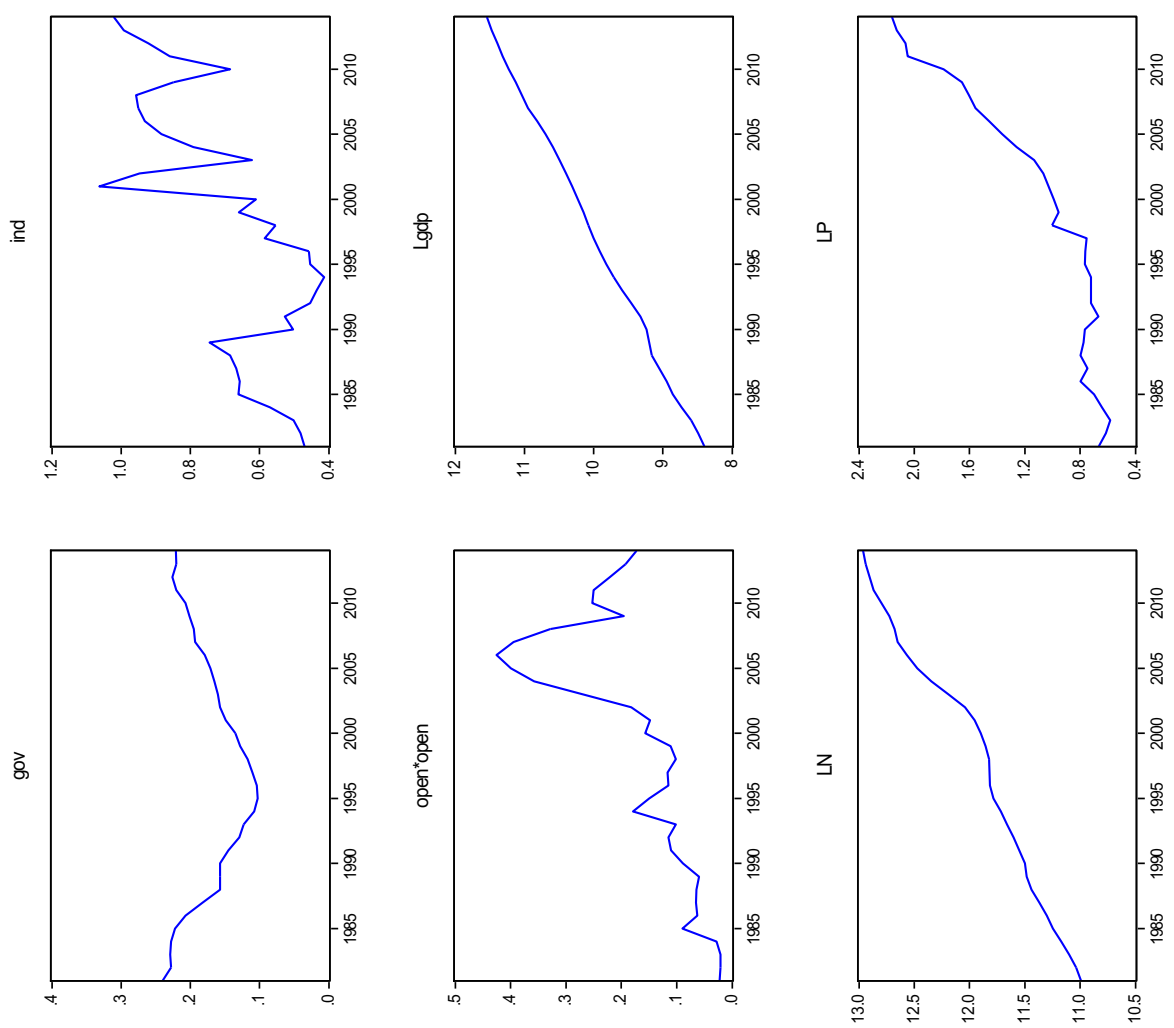

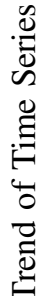
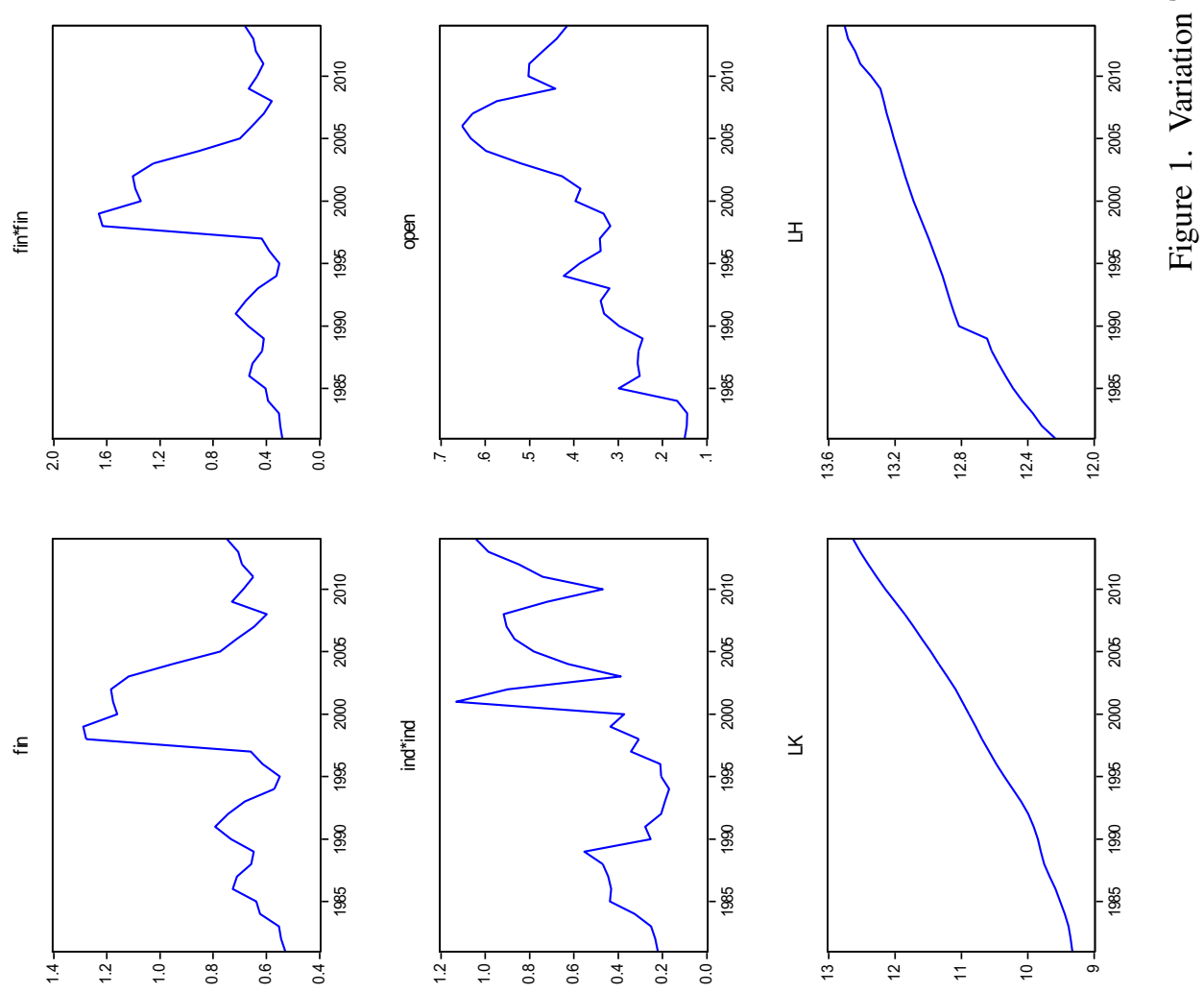
Table 2. Variables Stationary Test

\begin{tabular}{|c|c|c|c|}
\hline Variable & Test Type $(C, T, K)$ & ADF Test Value & Conclusion \\
\hline $\operatorname{Ln} Y$ & $(C, T, 1)$ & -2.71 & Non-stationary \\
\hline$d \operatorname{Ln} Y$ & $(C, T, 0)$ & $-4.15 * * *$ & Stationary \\
\hline $\operatorname{Ln} K$ & $(C, T, 1)$ & -2.89 & Non-stationary \\
\hline$d \ln K$ & $(C, T, 0)$ & $-3.50 *$ & Stationary \\
\hline $\ln H$ & $(C, T, 1)$ & -2.46 & Non-stationary \\
\hline$d \ln H$ & $(C, T, 0)$ & $-2.56^{*}$ & Stationary \\
\hline $\operatorname{Ln} N$ & $(C, T, 1)$ & -2.25 & Non-stationary \\
\hline$d \ln N$ & $(C, T, 0)$ & $-2.65^{*}$ & Stationary \\
\hline $\operatorname{Ln} P$ & $(C, T, 1)$ & -0.96 & Non-stationary \\
\hline$d \ln P$ & $(C, T, 0)$ & $-5.32 * * *$ & Stationary \\
\hline ind & $(C, T, 0)$ & -2.86 & Non-stationary \\
\hline dind & $(C, T, 0)$ & $-6.48 * * *$ & Stationary \\
\hline ind $^{2}$ & $(C, T, 1)$ & -3.13 & Non-stationary \\
\hline dind $^{2}$ & $(C, T, 1)$ & $-5.59 * * *$ & Stationary \\
\hline Gov & $(C, T, 1)$ & -1.54 & Non-stationary \\
\hline dgov & $(C, T, 0)$ & $-3.59 * *$ & Stationary \\
\hline Fin & $(C, T, 1)$ & -1.76 & Non-stationary \\
\hline$d$ fin & $(C, T, 1)$ & $-4.54 * * *$ & Stationary \\
\hline fin $^{2}$ & $(C, T, 0)$ & -1.76 & Non-stationary \\
\hline$d$ fin $^{2}$ & $(C, T, 1)$ & $-4.65 * * *$ & Stationary \\
\hline Open & $(C, T, 1)$ & -1.31 & Non-stationary \\
\hline dopen & $(C, T, 0)$ & $-5.20 * * *$ & Stationary \\
\hline open $^{2}$ & $(C, T, 1)$ & -1.85 & Non-stationary \\
\hline$d$ open $^{2}$ & $(C, T, 1)$ & $-4.32 * * *$ & Stationary \\
\hline
\end{tabular}

Notes: (1) $d$ represents the first-order difference of a variable; (2) test type ( $C$, $T, K)$, where $C, T$ represent the intercept and trend in the test equation, respectively, $K$ represents lag order; (3) $* * *, * *, *$ represent significance level at $1 \%, 5 \%, 10 \%$.

the RSS without the quadratic term, so the quadratic term is removed. In fact, this phenomenon indicates that the relationship between total factor productivity and government intervention is linear. It can be seen from $M 5$ that when government intervention increases $1 \%$, China's economy declines $0.98 \%$. The government intervention could hinder economic growth by affecting TFP. $M 1$ is the regression result in which TFP processed as a fixed parameter. We can see that the output elasticities of physical capital, human capital, energy consumption and environmental losses are 0.59, 0.70, 0.36 and 0.29. The environment, as a key natural capital, becomes a booster of China's economic development, indicating that China's economy has not along the strong sustainable development path. $M 2$ is the regression result after introducing industrial structure factor. The coefficients of industrial structure variable and its quadratic term both pass the test of significance. Its quadratic coefficient is negative, which indicates that the relationship between industrial structure and its marginal growth effect is inverted U-shaped. The result means that China's 
Table 3. Regression Results

\begin{tabular}{|c|c|c|c|c|c|c|}
\hline & $M 1$ & $M 2$ & M3 & $M 4$ & M5 & M6 \\
\hline$c$ & $\begin{array}{l}-9.47 * * * \\
(-11.20)\end{array}$ & $\begin{array}{l}-10.03 * * * \\
(-12.34)\end{array}$ & $\begin{array}{l}-5.62 * * * \\
(-4.12)\end{array}$ & $\begin{array}{l}-7.40 * * * \\
(-4.26)\end{array}$ & $\begin{array}{l}-5.82 * * * \\
(-3.17)\end{array}$ & $\begin{array}{l}-8.96 \\
(-1.30)\end{array}$ \\
\hline$K$ & $\begin{array}{l}0.59 * * * \\
(8.74)\end{array}$ & $\begin{array}{l}0.59 * * * \\
(9.15)\end{array}$ & $\begin{array}{l}0.64 * * * \\
(11.69)\end{array}$ & $\begin{array}{l}0.54 * * * \\
(6.93)\end{array}$ & $\begin{array}{l}0.54 * * * \\
(6.95)\end{array}$ & $\begin{array}{l}0.46^{* * * *} \\
(3.14)\end{array}$ \\
\hline$H$ & $\begin{array}{l}0.70 * * * \\
(6.22)\end{array}$ & $\begin{array}{l}0.76 * * * \\
(7.08)\end{array}$ & $\begin{array}{l}0.38 * * * \\
(2.87)\end{array}$ & $\begin{array}{l}0.53 * * * \\
(2.78)\end{array}$ & $\begin{array}{c}0.22 \\
(1.15)\end{array}$ & $\begin{array}{c}0.16 \\
(0.19)\end{array}$ \\
\hline$N$ & $\begin{array}{l}0.36 * * * \\
(3.65)\end{array}$ & $\begin{array}{l}0.34 * * * \\
(3.58)\end{array}$ & $\begin{array}{l}0.32 * * * \\
(4.18)\end{array}$ & $\begin{array}{l}0.42 * * * \\
(3.17)\end{array}$ & $\begin{array}{l}0.62 * * * \\
(3.45)\end{array}$ & $\begin{array}{l}0.64 * * \\
(2.22)\end{array}$ \\
\hline$P$ & $\begin{array}{l}0.29 * * * \\
(4.03)\end{array}$ & $\begin{array}{l}0.30 * * * \\
(4.46)\end{array}$ & $\begin{array}{l}0.14 * * * \\
(1.92)\end{array}$ & $\begin{array}{l}0.14^{*} \\
(1.96)\end{array}$ & $\begin{array}{l}0.20^{* *} \\
(2.56)\end{array}$ & $\begin{array}{l}0.31 * * \\
(2.48)\end{array}$ \\
\hline ind & & $\begin{array}{l}0.75^{* *} \\
(2.29)\end{array}$ & $\begin{array}{l}0.82 * * * \\
(3.01)\end{array}$ & $\begin{array}{l}0.92 * * \\
(2.52)\end{array}$ & $\begin{array}{c}0.63^{*} \\
(1.89)\end{array}$ & $\begin{array}{c}0.45 \\
(0.45)\end{array}$ \\
\hline ind $^{2}$ & & $\begin{array}{l}-0.46^{* *} \\
(-2.06)\end{array}$ & $\begin{array}{l}-0.47 * * * \\
(-2.56)\end{array}$ & $\begin{array}{l}-0.54 * * \\
(-2.27)\end{array}$ & $\begin{array}{c}-0.34 \\
(-1.59)\end{array}$ & $\begin{array}{c}-0.22 \\
(-0.35)\end{array}$ \\
\hline gov & & & $\begin{array}{l}-1.52 * * * \\
(-3.70)\end{array}$ & $\begin{array}{l}-1.15^{*} \\
(-2.52)\end{array}$ & $\begin{array}{l}-0.98 * * \\
(-2.38)\end{array}$ & $\begin{array}{l}-0.02 * * \\
(-0.01)\end{array}$ \\
\hline fin & & & & $\begin{array}{c}-0.73^{*} \\
(-1.80)\end{array}$ & $\begin{array}{l}-0.75^{* *} \\
(-2.11)\end{array}$ & $\begin{array}{l}-0.93 * * \\
(-1.11)\end{array}$ \\
\hline fin $^{2}$ & & & & $\begin{array}{c}0.41 * \\
(1.89)\end{array}$ & $\begin{array}{l}0.45^{* *} \\
(2.35)\end{array}$ & $\begin{array}{c}0.58 * * \\
(1.47)\end{array}$ \\
\hline open & & & & & $\begin{array}{l}1.10^{* *} \\
(2.77)\end{array}$ & $\begin{array}{l}1.05^{* *} \\
(1.24)\end{array}$ \\
\hline open $^{2}$ & & & & & $\begin{array}{l}-1.29 * * * \\
(-3.07)\end{array}$ & $\begin{array}{l}-1.57 * * * \\
(-1.60)\end{array}$ \\
\hline DW value & 1.0764 & 1.2768 & 1.1811 & 1.288 & 1.8211 & 1.7504 \\
\hline RSS & 0.0529 & 0.0424 & 0.0277 & 0.0239 & 0.0166 & 0.0164 \\
\hline$R^{2}$ & 0.9982 & 0.9986 & 0.9991 & 0.9992 & 0.9994 & 0.9990 \\
\hline Adjusted $R^{2}$ & 0.9980 & 0.9983 & 0.9988 & 0.9989 & 0.9992 & 0.9985 \\
\hline$P$-value & 0.0000 & 0.0000 & 0.0000 & 0.0000 & 0.0000 & 0.0000 \\
\hline
\end{tabular}

Notes: Figures in parentheses are $t$-statistics of estimated coefficients. ***, **, * represent significance level at $1 \%, 5 \%, 10 \%$, respectively.

economy grows with continuous development of tertiary industry, but the effect pulled by industrial structure on economy weakens when percent of tertiary industry outstrips a certain value. The reason may be that industrial structure deviates from the optimal will have a negative effect on economic development. Increase in proportion of tertiary industry can compress presence of the primary industry and the secondary industry, while these two industries are cornerstone of China's economy. Comparing $M 1$ and $M 2$, the output elasticities of physical capital, human capital, energy consumption and environmental losses do not present substantial change.

$M 3$ is the regression result after adding government intervention based on M2. The government intervention has a negative correlation with economic development. Compared 
with $M 2$, elasticity of human capital sharply declines from 0.76 to 0.38 , and elasticity of environment loss declines from 0.3 to 0.14 . The change indicates that government intervention leads to resources mismatch, which have an impact on labor market, and it further affects labor productivity. The result is same as the study of Zhang. He argued that local government investment behavior has no significant impact on employment growth (Zhang et al., 2011). However, government intervention brings positive benefits for environment. The result is consistent with some existing conclusions. Ding and Deng (2007) found that government intervention could reduce the negative correlation between natural resources and economic growth. Liu (2011) argued that cracking "resource curse" phenomenon in the resource city needs government intervention.

$M 4$ is the regression result that added financial structure variable based on M3. Both financial structure and its quadratic term pass the test of significance, and the quadratic coefficient is positive. The two coefficients indicate that the relationship between financial structure and its marginal growth effect is U-shaped. Its effect gradually weakens before a certain value reaching. After the certain value, financial structure increasingly brings dividends to economy. Our result is consistent with the view of Chen et al. (2007) that China's financial fails to promote economic growth in the short term, but the long-term effect on economy exists. The coefficients of other variables in $M 4$ change slightly, which shows that the coefficients are stable and reliable. M5 is the regression result of Equation (4) without quadratic term of government intervention. The coefficients of degree of openness and its quadratic term are significant, and its quadratic coefficient is negative. The coefficients indicate that there is an inverted-U relationship between openness and its marginal growth effect. The initial openness promotes China's economic growth, but this effect gradually weakens after peak value reached. Compared with $M 4$, we can find that the coefficient of human capital does not pass significance test, and it reaches the lowest value. Although physical capital passes significance test, its value also reaches the minimum of five models. The reason may be that China attracts foreign investment and introduces advanced technology and management experience by openness; the introduction suppresses the space of domestic physical capital and labor. From another perspective, China's resources have the potential for releasing.

From the regression results, we can roughly estimate China's optimal value of industrial structure. The value has the best effect on economy, and it is about $86.64 \%$. According to the average proportion of primary industry $4.5 \%$ since 2010 , then the preferred tertiary industry and secondary industry should account for $51 \%$ and $44 \%$, respectively. In fact, China's economic growth rates were rising during 1998-2007, and its secondary industry and tertiary industry accounted for a reasonable range of the optimal value calculated above. However, China's industrial structure changed significantly from 2010 to 2015 . Its secondary industry declined from $57.4 \%$ in 2010 to $41.6 \%$ in 2015, whereas the tertiary industry increased from $39.0 \%$ in 2010 to $53.7 \%$ in 2015 (People's Republic of China, 2015). China's industrial structure gradually deviated from the optimal. From the perspective of degree of openness, according to the equation of regression coefficients, we can get that the appropriate degree of openness is about 42.64\%. However, in accordance with the actual situation of China's foreign trade, 
Table 4. Test for Heteroskedasticity

\begin{tabular}{lrcc}
\hline$F$-statistic & 1.46 & Problem. $F(11,22)$ & 0.2177 \\
Obs. $R^{2}$ & 14.33 & Problem. Chi(11) & 0.2155 \\
Scaled explained SS & 6.79 & Problem. Chi(11) & 0.8161 \\
\hline
\end{tabular}

degree of openness has been maintained at about 50\%. It reveals that China's economy has a greater dependence on the world's economy, and its growth is mainly due to foreign trade, rather than domestic consumption. The structure makes China's economy more susceptible to the global economic downturn. Being into the "new normal", industrial structure and degree of openness that deviate from optimal allocation may be the reason for the shift of China's economic growth.

From the DW value of $M 5$, it can be seen that the model regression residuals do not have strong first-order autocorrelation. In order to illustrate the robustness of the results, we use the White test for heteroskedasticity. The results are shown in Table 4. From the table, we can conclude that the White test cannot reject the original hypothesis that all variables are same variance. The conclusion indicates that the regression results of $M 5$ are reliable. In addition, the explanatory variables, such as $K, L, N, P$ and so on, have different effects on GDP, and the variables may also be affected by GDP. The effects may lead to endogenous problems. To illustrate the effectiveness of regression results, we chose lagged variables of $K, L, N, P$ as the instrumental variable and use 2SLS method to estimate formula (4). The results are shown in the last column in Table 3. We find that coefficients obtained from 2SLS are basically consistent with those obtained by original regression.

\subsection{Decomposition of China's economic growth}

With the implementation of the reform and opening-up, China's economic construction has made remarkable achievements in the world. Its GDP jumps to 63.6139 trillion Yuan in 2014 from 364.5 billion Yuan in 1978 (People's Republic of China, 2015). With the economic growth, China has jumped to a middle-income country from the bottom-income country. It is a commendable success for China, such a country with low starting point, huge population and weak economic basis. This is why many scholars call it "China's miracle". It is worth investigating what pulled so shocked growth.

Next, this paper will decompose China's economic growth into three parts, namely, contributions of factor inputs, ecological loss and total factor productivity, where factor inputs include physical capital and human capital, ecological losses include energy consumption and environmental pollution and TFP includes industrial structure, financial structure, the degree of openness and government intervention. Utilizing the elasticity of each element, we can obtain the sources of China's economic growth during 1982 and 2014 according to formula (6). The corresponding results are in Table 5.

From Table 5, during 1982 and 2014, China's average economic growth rate is $10.02 \%$. Among factor inputs, ecological loss and total factor productivity, economic growth rate driven by factor inputs is $6.89 \%$, where physical capital accounts for $85.78 \%$. The physical 


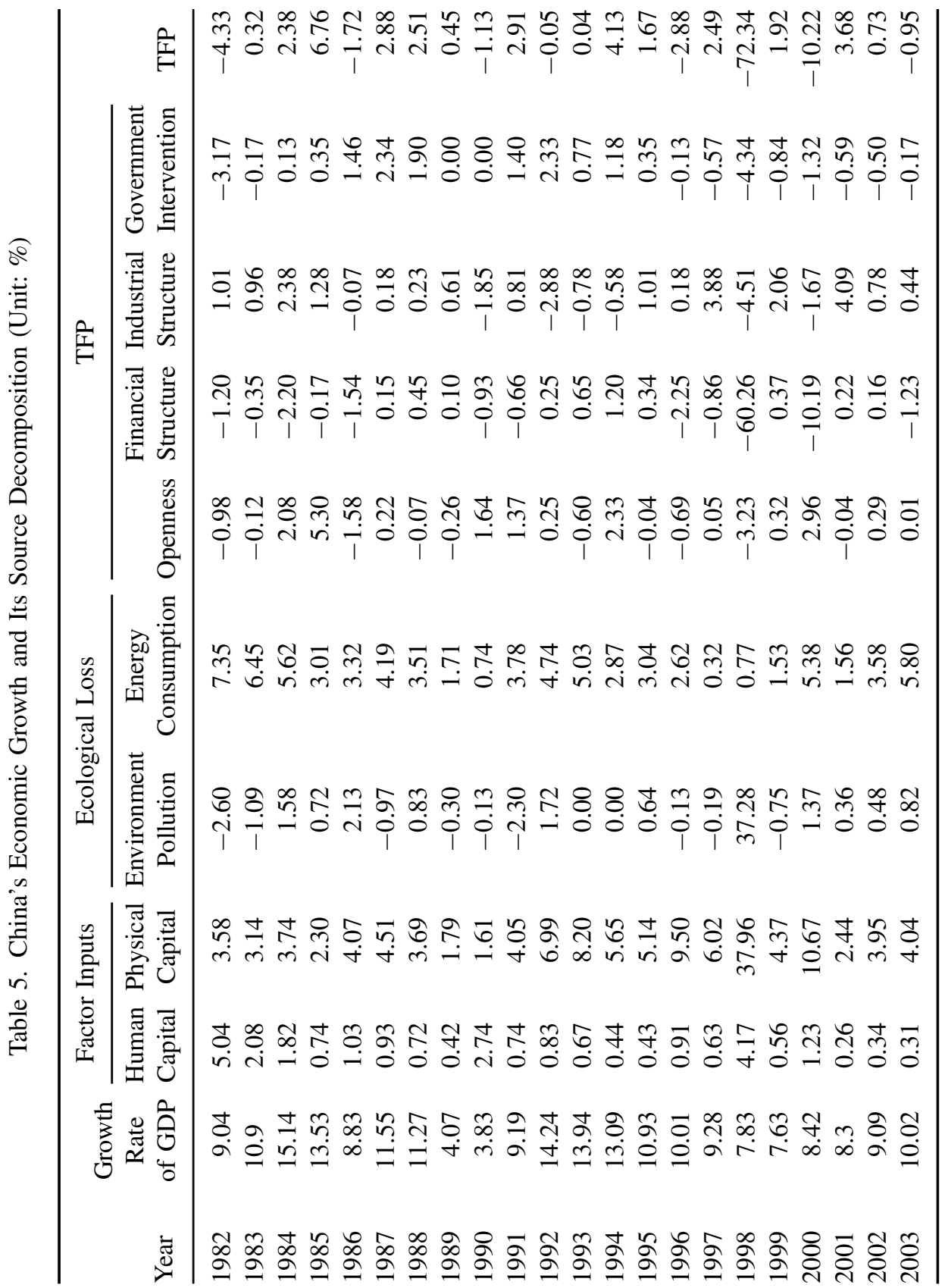




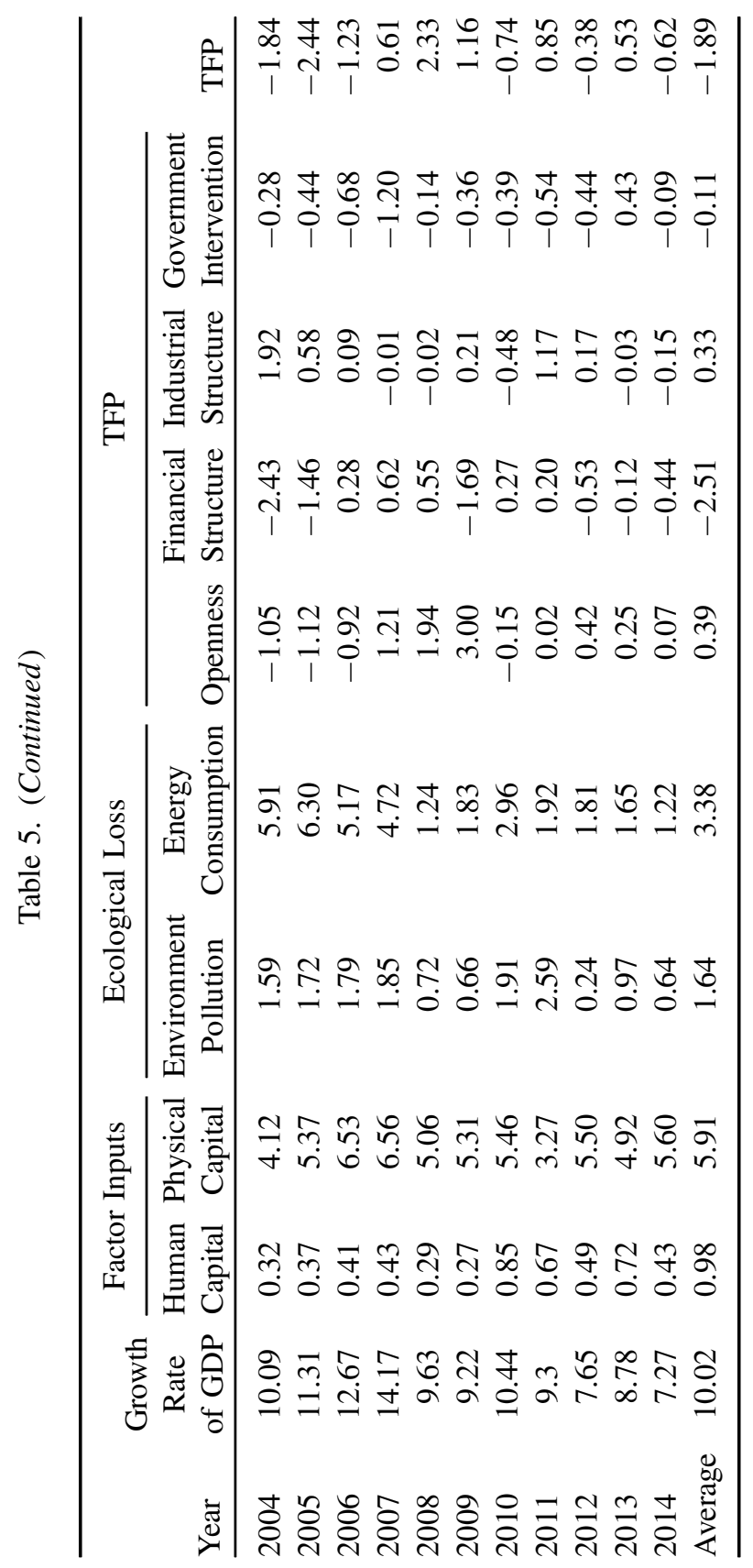


capital plays an important role in China's economic development, and it is the primary driving force. Economic growth rate related to human capital is $0.98 \%$, and its contribution to economic growth rate is $9.78 \%$. Economic growth rate driven by energy consumption is $3.38 \%$, and growth rate related to environment is $1.64 \%$. Since 2000 , environmental loss has contributed positively to economic growth. In order to achieve strong sustainable development, China must reduce dependence on environment and strengthen green economy.

However, the economic growth rate related to TFP is low. Its average value only is $-1.89 \%$. The openness is an important way to improve total factor productivity. Adjustment of industrial structure can similarly drive total factor productivity improving. The role of government is undesired. China's financial structure brings resistance to TFP. The resistance is bigger than the effect that openness facilitated on total factor productivity, so that the role of TFP is not illustrious.

From all sources of economic growth, we can conclude that China's economic growth is still extensive and unsustainable. China should transform economic development mode to rely more on TFP.

According to the overall trend of China's economic growth rate from 1992 to 2014, we can divide this period into three stages. The first one is 1992-1997. In this stage, China's economic growth rate declines. The second one is 1998-2007. In this stage, China's economic growth rate soars to $14 \%$ from 8\%. The third one is from 2009 to 2014. The economic growth rate shows a downward trend from 2009, and it gradually departs from the high growth area. In addition, the Asian financial crisis broke out in 1998, the subprime mortgage crisis broke out in the United States in 2008 and China's economy has gradually entered the "new normal" stage since 2009. Combined with the above major events and time-varying point of China's economic growth rate, this paper divides the years when China enters the market economy into three periods, namely, 1992-1997, 1998-2007 and 2008-2014, to make dynamic analysis.

(1) 1992-1997. During this period, China's economic growth rate in 1992 rapidly increases to $14.24 \%$, which is the second peak since 1981. Although the growth rate declines in the following years, they are still higher than $9 \%$. The reason is that Deng Xiaoping went around and inspected south of China and published the famous southern conversation in 1992, he promptly and deeply answered some major issues related to "what is socialism and how to build socialism". The conversation greatly emancipated people's minds, strengthened the people's socialist beliefs and greatly promoted the process of China's reform and opening-up. In the same year, China basically finished economic order rectification. These events make the economic growth rate in 1992 climb to the peak value. During 1992 and 1997, China's economic growth rate related to physical capital is $6.92 \%$, and the related grow rate of human capital and energy inputs is $0.65 \%$ and $3.10 \%$, respectively. The economic growth rate related to total factor productivity is $0.90 \%$. The contribution of environment is not obvious. These numbers suggest that China's economic growth momentum is physical capital, and TFP, energy investment and human capital play a slight role. From the 
perspective of TFP, economic growth driven by openness is $0.22 \%$, and that of industrial structure and government intervention is $0.14 \%$ and $0.66 \%$, respectively. The contribution of financial structure is negative. As we can see, during this period, government intervention is the leading source of improving TFP. Adjustment of economic structure contributes little to TFP. This stage is the beginning of establishment of socialist market economy; government intervention in economy plays a positive role due to the positive contribution to TFP.

(2) 1998-2007. China's GDP growth rates present a substantially "U"-shaped variation between 1992 and 2007. The growth rate of 1998 is in the relative valley position due to the impact of Asian financial crisis. During 1998 and 2007, China's average economic growth rate is $9.95 \%$, and the physical capital remains the main driver for China's economic growth. Economic growth rate driven by it is $8.60 \%$, and its contribution reaches $86.43 \%$. To get out of financial crisis shadow, China's government adopted the action increasing physical capital investment, especially in infrastructure. The action has played a role in steadying growth in short term and increasing effective physical capital accumulation for next high-speed growth. The economic growth rate related to human capital presents a slight decline compared with the value of 19921997. Economic growth rate related to energy consumption is $4.07 \%$. It increases compared with that of previous period, and its contribution to economy reaches $40.90 \%$, the value closes to contribution of physical capital. Economic growth rate related to environment is $4.65 \%$. The number suggests that China's extensive development characteristic that depending on energy consumption and environment pollution is further exposing and its environmental conditions have not been improved. The economic growth rate related to TFP is $-8.21 \%$, and there is a substantial decline compared with the value of 1992-1997. Economic growth rate related to openness and industrial structure is $-0.16 \%$ and $0.38 \%$, respectively. Economic growth rate driven by government intervention is $-1.04 \%$. The contribution of financial structure to economic growth is still negative. During this period, industrial structure has become an important approach to promoting TFP. The reason is that the proportion of primary industry declined from $17.32 \%$ in 1998 to $10.97 \%$ in 2007 , the proportion of secondary industry rose steadily and proportion of tertiary industry significantly increased. Adjustment of industrial structure can make labor productivity improve, but the secondary and tertiary industries can make labor productivity improve rapidly compared with primary industry. Therefore, adjustment of industrial structure became the primary factor to promote TFP. Openness still presents a positive effect on economy.

(3) 2008-2014. With the spread of subprime crisis broke out in the United States, China's economic growth rate gradually declines. During this period, China's average rate is $8.90 \%$. The economic growth related to physical capital is $5.02 \%$, and its contribution is $56.40 \%$. The reason for such high contribution is that China developed a "four trillion" stimulus program to expand domestic demand and steady economic growth after subprime crisis out broke. The economic growth rate related to human capital is $0.53 \%$; it decreases compared with the value of previous period. The contribution of energy consumption to economic growth is $20.22 \%$; in the meantime, economic 
growth driven by environment is $1.10 \%$. Although China has strengthened the construction of ecological civilization since 2007, its environment problem is still grim. The economic growth related to TFP is $0.45 \%$. Industrial structure and openness are still two important ways to promote TFP, and their related economic growth is $0.12 \%$ and $0.79 \%$, respectively. Both contributions of financial structure and government intervention are negative. With advancement of marketization, China's government intervention to market affects the efficiency of resource allocation, distorts the elements flow direction and weakens the market regulation. In turn, it reduces the labor productivity and hinders total factor productivity from improvement.

\section{The Short-Term Economic Growth of China}

The concern of macroeconomic is not only the long-term growth of total economy, but also the stability of economic operation in short term. According to the previous formulas (6) and (7), the economic growth rate can be decomposed as linear sum of growth rate of the total factor productivity and input factors. Then, the change of total factor productivity and input factors would induce the change of economic growth. To this end, this paper utilizes a VAR model to investigate the change of China's economic growth in short run by EViews7.

\subsection{VAR model}

As the application of VAR model requires the stability of relevant variables in the system, this paper first does unit root test to identify the stability of relevant variables. According to Figure 2, all the time series do not show a clear trend, so neither trend nor intercept is

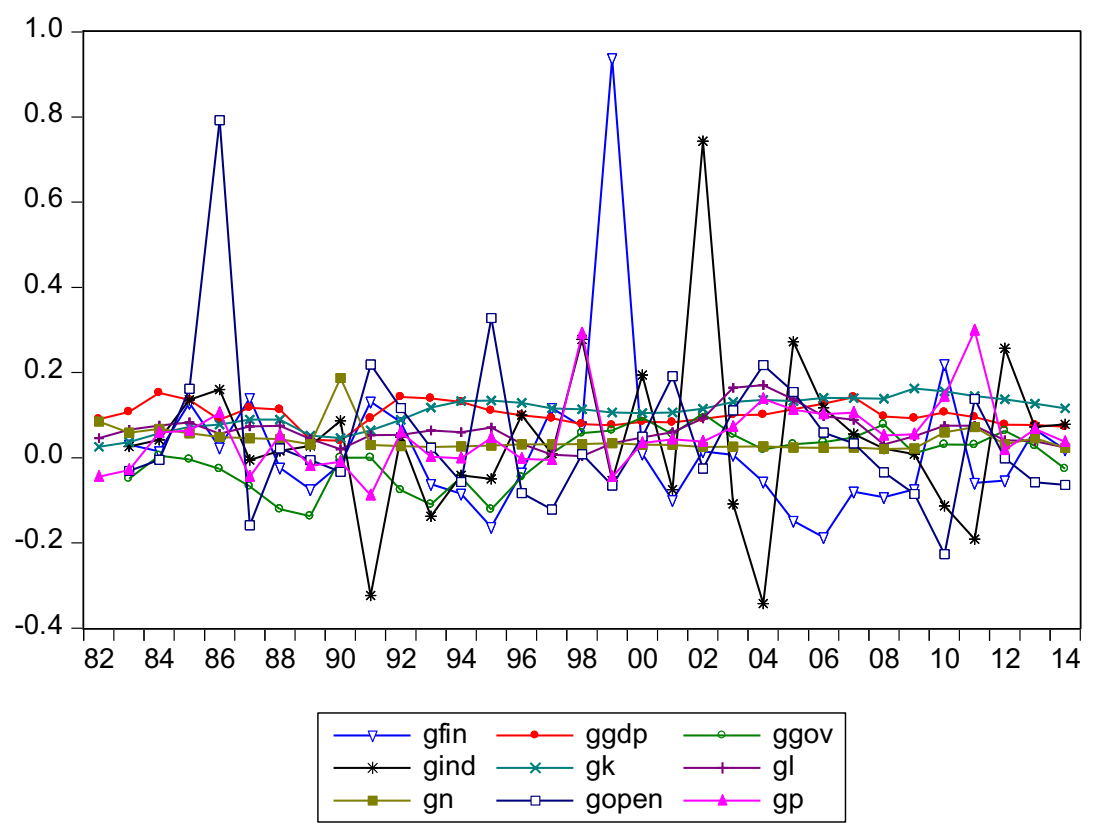

Figure 2. Trend of Growth Rate of Each Variable 
Table 6. Unit Root Test

\begin{tabular}{|c|c|c|c|c|c|}
\hline \multirow[b]{2}{*}{ Variable } & \multicolumn{3}{|c|}{ Test Critical Values } & \multirow[b]{2}{*}{$t$-Statistic } & \multirow[b]{2}{*}{ Prob. } \\
\hline & $1 \%$ & $5 \%$ & $10 \%$ & & \\
\hline$g_{\text {gdp }}$ & -3.6617 & -2.9604 & -2.6192 & -4.1466 & 0.0030 \\
\hline$g_{K}$ & -3.6617 & -2.9604 & -2.6192 & -3.0340 & 0.0140 \\
\hline$g_{H}$ & -3.6617 & -2.9604 & -2.6192 & -2.6711 & 0.0904 \\
\hline$g_{N}$ & -3.6617 & -2.9604 & -2.6192 & -5.2400 & 0.0002 \\
\hline$g_{P}$ & -3.6617 & -2.9604 & -2.6192 & -5.3182 & 0.0001 \\
\hline$g_{\text {ind }}$ & -3.6617 & -2.9604 & -2.6192 & -6.7650 & 0.0000 \\
\hline$g_{\text {gov }}$ & -3.6617 & -2.9604 & -2.6192 & -2.8034 & 0.0818 \\
\hline$g_{\text {fin }}$ & -3.6617 & -2.9604 & -2.6192 & -4.7666 & 0.0006 \\
\hline$g_{\text {open }}$ & -3.6617 & -2.9604 & -2.6192 & -5.6002 & 0.0001 \\
\hline
\end{tabular}

included in test equation when using the ADF test. The change rate of variables such as physical capital, human capital, energy consumption, environmental loss, financial structure, industrial structure, government intervention and degree of openness is stable at $10 \%$ significance level (Table 6), and VAR model could be established.

Table 7 shows the LR, FPE, AIC, SC and HQ values for the VAR model with lag period from 0 to 2 . It can be seen that the better order is 2 ; then the specific model can be estimated as follows:

$$
\begin{aligned}
& \left(\begin{array}{c}
\text { fin }_{t} \\
\operatorname{gpd}_{t} \\
\text { gov }_{t} \\
\text { ind }_{t} \\
K_{t} \\
L_{t} \\
N_{t} \\
\text { open }_{t} \\
P_{t}
\end{array}\right)=\left(\begin{array}{c}
1.0323 \\
0.1179 \\
0.2619 \\
0.6903 \\
0.0499 \\
0.1268 \\
0.1417 \\
-0.6975 \\
-0.2874
\end{array}\right) \\
& +\left(\begin{array}{ccccccccc}
0.0110 & -3.8287 & 0.6069 & 0.0806 & 5.8797 & -2.0590 & -3.5076 & -0.0585 & 2.3330 \\
0.0022 & 0.3978 & 0.1533 & -0.0276 & 1.1720 & -0.2040 & -0.1628 & 0.0571 & 0.0042 \\
-0.1463 & 0.6366 & 0.8711 & -0.0843 & -2.6333 & 0.4216 & -0.8497 & 0.0627 & 0.0884 \\
-0.5629 & 4.5722 & 1.3718 & -0.6744 & -16.2592 & 0.6649 & -2.4832 & 0.3725 & -0.2565 \\
-0.0129 & -0.0144 & 0.1778 & -0.0271 & 1.1124 & -0.0282 & -0.0634 & 0.0221 & -0.0315 \\
-0.0033 & -0.7532 & 0.2553 & 0.0125 & 1.2178 & 1.0503 & -0.1913 & -0.0030 & 0.0217 \\
-0.0401 & -0.5629 & -0.1397 & -0.0126 & -1.3790 & 0.3940 & -0.2996 & -0.0727 & 0.0629 \\
0.3271 & -1.0072 & 1.6272 & 0.0280 & -1.6853 & 4.1571 & 0.9866 & -0.3576 & -0.5314 \\
0.1446 & 0.3887 & 0.3414 & -0.0266 & -0.6343 & 0.5616 & 0.3738 & -0.1523 & -0.3061
\end{array}\right)\left(\begin{array}{c}
\mathrm{fin}_{t-1} \\
\operatorname{gdp}_{t-1} \\
\operatorname{gov}_{t-1} \\
\text { ind }_{t-1} \\
K_{t-1} \\
L_{t-1} \\
N_{t-1} \\
\text { open }_{t-1} \\
P_{t-1}
\end{array}\right)
\end{aligned}
$$




$$
\begin{aligned}
& +\left(\begin{array}{ccccccccc}
-0.2451 & -1.4680 & -1.5619 & 0.2005 & -8.7233 & -0.9505 & -0.1882 & 0.0565 & 0.2280 \\
-0.0160 & -0.5708 & -0.1681 & -0.0013 & -1.1790 & 0.2416 & -0.1336 & 0.0187 & 0.0281 \\
-0.0521 & -0.9655 & -0.2846 & -0.0190 & 1.5412 & -0.9546 & -1.4102 & -0.0913 & 0.4499 \\
-0.3013 & -0.5520 & 1.0810 & -0.4219 & 10.7604 & -3.8558 & -2.9932 & 0.0376 & 1.0292 \\
-0.0181 & 0.0185 & -0.0135 & -0.0219 & -0.4217 & -0.0515 & -0.1420 & 0.0124 & -0.0045 \\
-0.0178 & 0.1103 & -0.0919 & -0.0129 & -1.5344 & -0.3011 & -0.2721 & 0.0179 & -0.0224 \\
-0.0190 & 0.4753 & 0.0664 & -0.0240 & 0.6157 & -0.3655 & -0.0193 & -0.0047 & 0.0747 \\
0.0708 & 6.3082 & -0.0772 & -0.1868 & 0.7377 & -1.0820 & 2.4954 & 0.0105 & -0.9677 \\
-0.0637 & 1.0114 & 0.3669 & -0.0204 & 2.0526 & 0.2494 & 0.9077 & 0.0023 & -0.5274
\end{array}\right) \\
& \times\left(\begin{array}{c}
\operatorname{fin}_{t-2} \\
\operatorname{gdp}_{t-2} \\
\operatorname{gov}_{t-2} \\
\operatorname{ind}_{t-2} \\
K_{t-2} \\
L_{t-2} \\
N_{t-2} \\
\operatorname{open}_{t-2} \\
P_{t-2}
\end{array}\right)+\left(\begin{array}{c}
\varepsilon_{1 t} \\
\varepsilon_{2 t} \\
\varepsilon_{3 t} \\
\varepsilon_{4 t} \\
\varepsilon_{5 t} \\
\varepsilon_{6 t} \\
\varepsilon_{7 t} \\
\varepsilon_{8 t} \\
\varepsilon_{9 t}
\end{array}\right)
\end{aligned}
$$

The stability of the above model is required to be tested, because if the model is unstable, some results will not be valid (e.g., the standard error of the impulse response function). In this paper, we use the AR root to test. It can be seen from Figure 3 that all unit roots fall within the unit root circle, indicating that VAR satisfies the stability condition. Here, we use the impulse response function and variance decomposition to analyze the interaction between selected variables and economic growth rate.

\subsection{Impulse response analysis of China's economic growth}

According to the regular pattern of economic cycle, we select 10 as the lag time for impulse response analysis. The result is shown in Figure 4. In this figure, the horizontal coordinate represents the time interval after the pulse occurred, and the vertical coordinate represents the impact, as can be seen from Figure 4.

Given one unit impulse to GDP, economic growth changes positively in the first three phases and reaches a positive maximum in the second stage. After the third stage, the respond becomes negative and gradually converges after the fourth phase. This response pattern shows that the change of economic growth has inertial characteristics, in the sense that short-term economic changes will bring potential lag changes. Overall, economic

Table 7. Lag Period Selection Criteria

\begin{tabular}{lcccccc}
\hline Lag & $\log L$ & LR & FPE & AIC & SC & HQ \\
\hline 0 & 372.52 & NA & $2.41 \mathrm{e}-22$ & -24.23 & -23.81 & -24.10 \\
1 & 501.85 & 172.43 & $1.22 \mathrm{e}-23$ & -27.46 & -23.25 & -26.11 \\
2 & 657.10 & $113.85^{*}$ & $5.27 \mathrm{e}-25^{*}$ & $-32.41^{*}$ & $-24.42^{*}$ & $-29.85^{*}$ \\
\hline
\end{tabular}


Inverse Roots of AR Characteristic Polynomial

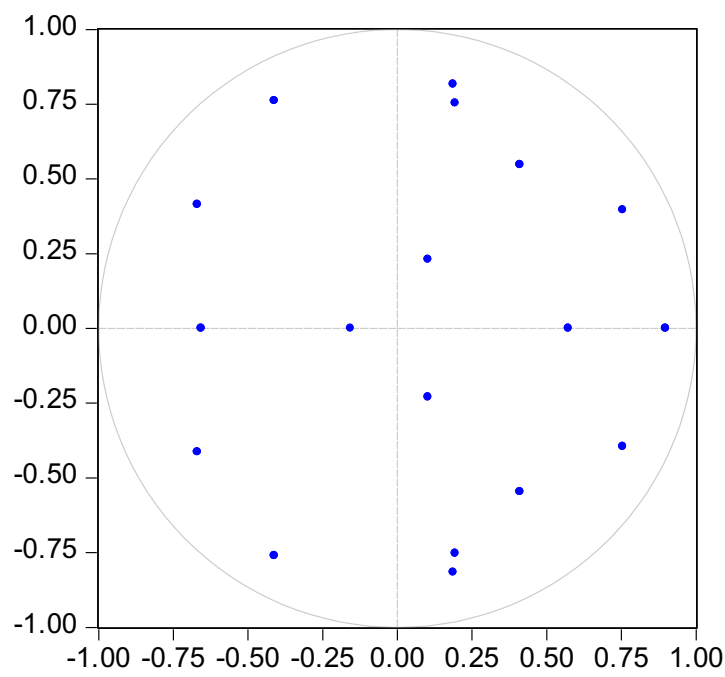

Figure 3. Unit Roots for VAR

growth changes have short-term effects, so that the current economic growth changes easily lead to changes in the latter two periods.

Given one unit positive impulse to $K$, economic growth does not change in the current period. It shows a positive change in the second stage, and the change reaches the maximum value. The response decreases from the third to the fourth stage, and it reaches the negative maximum in the fourth stage, then the response tends to converge. The $K$ would stimulate economic growth and promote economic changes, and this effect is short term. This shows that $K$ is a good way to stimulate economic growth, but it is not a good way to smooth economic growth changes. For example, in 2008, China took the means of increasing physical capital investment in order to get out of the shadow of financial crisis. The increased investment in infrastructure has not only played a stabilizing role in the growth in short term, but also increased the effective physical capital accumulation. However, this increased investment causes potential overcapacity in some industries and increases the potential downtown pressure and economic change risks (Zheng and Zhou, 2015).

Given $L$ one unit positive impulse, economic growth presents negative changes in the current stage, and it reaches the negative maximum in the second phase. After that, it tends to be stable. This pattern shows that the effect of human capital has a lag effect, and lag period is about 3 years. It is consistent with Wang's study findings (Wang et al., 2009). However, human capital is not a factor in expanding economic growth change. The impact of $N$ and $P$ on the change of economic growth is relatively small, close to 0 and shows a stable state from the current to the last stage, indicating that $N$ and $P$ could not expand economic growth changes. These facts show that China's economy is flexible enough to reduce energy consumption and environmental pollution, which provides China with enough confidence in turning toward strong sustainable development. 
Given fin one unit positive impulse, the economic growth negatively changes in the current stage, and the change continues being negative till the fifth period, then it turns positive. This pattern shows that the adjustment of the financial structure will have a negative impact on economic growth stability in the early period, but it would present a positive state in the end.

Given gov one unit positive impulse, economic growth positively changes in the first three periods, and afterwards it continues to be positive till gradually converging. This shows that the scale of government expenditure can lead to economic growth change. The reason may be that the government increases investment for the pursuit of economic growth. This increased investment by the government exceeds the optimal value and then influences private investment. Because government investment efficiency is lower than that of private investment, ultimately it affects the stability of economic operation. It may also be that the government intervenes the economy excessively by fiscal policy; the behavior makes the negative effect on economy higher than the positive effect of government intervention (Sang and Huang, 2016).

Given ind one unit positive impulse, economic growth negatively changes in the first three phases, and it reaches the negative maximum in second phase, but it positively changes from the fourth to the sixth phase and then it stabilizes. This pattern shows that the upgrading of industrial structure may affect the structure of factor endowment in the early stage and bring impact on the economy.

Given open one unit positive impulse, economic growth appears to respond positively in the first three periods, but the response turns negative in the fourth to the sixth stage and reaches the negative maximum in the fifth stage, then it gradually converges. Overall, the openness can drive China's economic growth, but it also increases short-term economic growth changes. The possible reason is that, on the one hand, China's economy is significantly export-oriented, especially since the accession to the WTO, the degree of dependence on foreign trade generally remains at around 50\%, which makes China's economy vulnerable to changes in export demand and trade conditions. On the other hand, most of China's trade objects are developed countries, but its trade products are mainly labor-intensive, the trade structure may also lead to economic growth changes.

\subsection{Variance decomposition of China's economic growth}

In order to measure the relative influence of various internal and external factors on macroeconomic stability, the variance of the impulse response function is decomposed. The results are shown in Table 8.

At the beginning of the period, financial structure has a greater impact on economic growth changes, reaching $9.66 \%$, and the impact is relatively stable. The government intervention, the industrial structure and the degree of openness contribute little to the economic growth change at the beginning, but their ability to explain the macroeconomic growth change increases with the going of time. In stable state, economic growth change contributions of government intervention, industrial structure and openness reach $5.81 \%$, $13.76 \%$ and $8.97 \%$. The contribution of physical capital to economic growth change is 
Table 8. Variance Decomposition

\begin{tabular}{lcccccccccc}
\hline Period & S.E. & fin & gdp & gov & ind & \multicolumn{1}{c}{$K$} & $L$ & $N$ & open & $P$ \\
\hline 1 & 0.12 & 9.66 & 90.34 & 0.00 & 0.00 & 0.00 & 0.00 & 0.00 & 0.00 & 0.00 \\
2 & 0.22 & 6.87 & 55.40 & 2.71 & 6.37 & 17.68 & 3.56 & 0.01 & 7.40 & 0.00 \\
3 & 0.26 & 6.07 & 46.37 & 6.14 & 8.56 & 17.57 & 3.46 & 0.02 & 11.66 & 0.15 \\
4 & 0.27 & 6.35 & 44.81 & 6.55 & 7.83 & 17.15 & 4.84 & 1.02 & 10.84 & 0.61 \\
5 & 0.28 & 5.98 & 43.56 & 5.63 & 11.07 & 14.66 & 6.82 & 1.44 & 10.24 & 0.60 \\
6 & 0.29 & 6.12 & 43.44 & 5.12 & 13.85 & 13.86 & 6.18 & 1.49 & 9.22 & 0.72 \\
7 & 0.31 & 7.72 & 42.23 & 5.28 & 13.82 & 13.41 & 6.35 & 1.46 & 9.05 & 0.69 \\
8 & 0.31 & 8.37 & 41.63 & 5.46 & 13.78 & 13.42 & 6.27 & 1.46 & 8.93 & 0.68 \\
9 & 0.31 & 8.55 & 41.24 & 5.40 & 13.83 & 13.64 & 6.25 & 1.48 & 8.87 & 0.76 \\
10 & 0.31 & 8.61 & 40.81 & 5.81 & 13.76 & 13.60 & 6.17 & 1.49 & 8.97 & 0.77 \\
\hline
\end{tabular}

relatively stable; it maintains at about $15 \%$. The contribution of human capital to economic change is increasing and it reaches $6.17 \%$ when stable. The contribution of ecological loss to economic growth change is smaller, about $2 \%$. Overall, the contribution of physical capital to economic growth change is the largest in terms of input factors. The contribution of total factor productivity to economic growth change reached $37.15 \%$. The contribution shows that the influence of total factor productivity on economic growth change could not be ignored. Steadily promoting the improvement of China's total factor productivity is an important action for China to realize strong sustainability.

In order to confirm the above conclusions, we use the data from Table 5 to derive Figures 5-9.

Observing Figure 5, China's economic growth rate and the economic growth rate driven by TFP have a relatively consistent trend. Between 1981 and 1983, they are in a rising

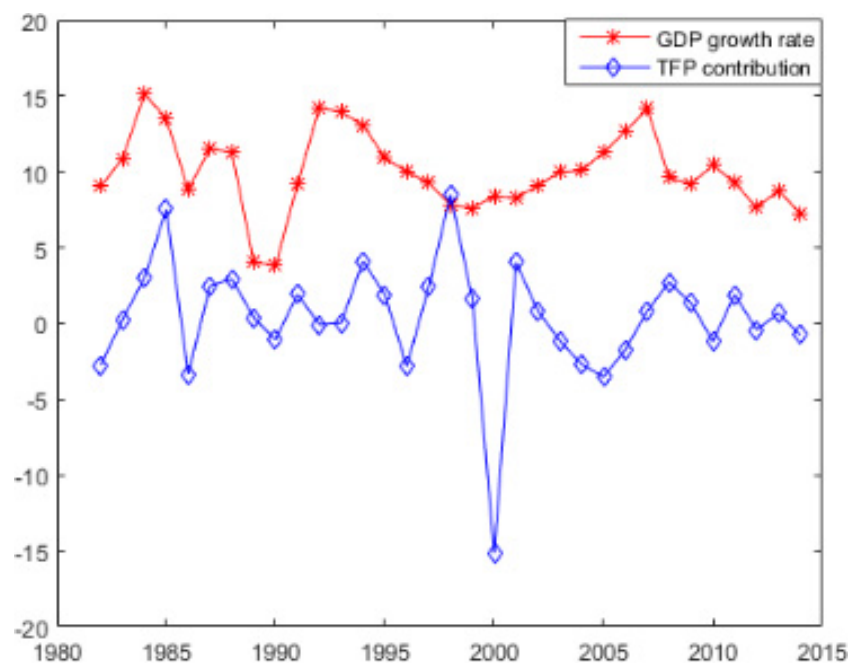

Figure 5. Economic Growth Rate Change with TFP 


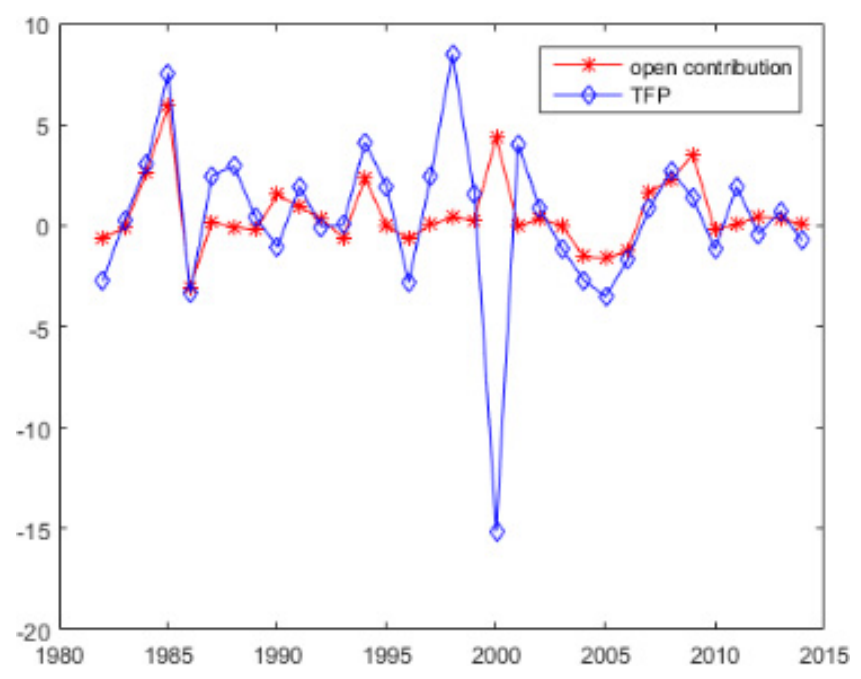

Figure 6. TFP with Contribution of Openness

stage. Then, they present a downward trend in the next four years and reach the minimum in 1990. They rise again in 1991. GDP growth rate presents a "U" type between 1991 and 2007. A small deviation from this, total factor productivity rises suddenly between 1996 and 1998, and its contribution decreases sharply in the following two years. The American Internet technology bubble burst in 2000, which greatly affects China's financial structure, and then influences TFP. The TFP reaches a minimum in 2000, and the change is relatively consistent with GDP. Since 2008, the GDP growth rate and economic growth rate driven by TFP are sliding.

In this paper, we attribute the influence factors of TFP to government intervention, openness, industrial structure and financial structure. Next, this paper analyzes the relation

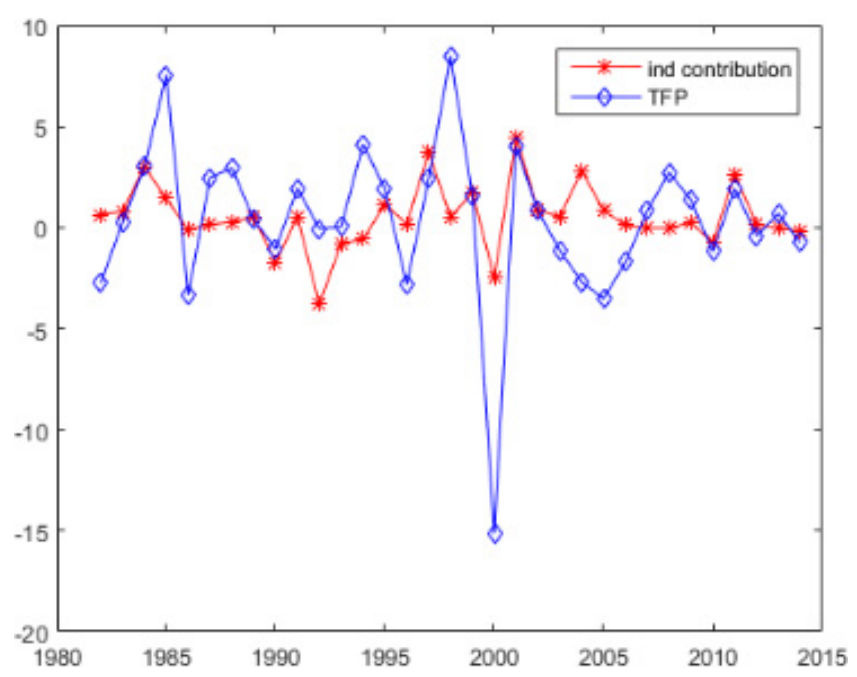

Figure 7. TFP with Contribution of Industrial 


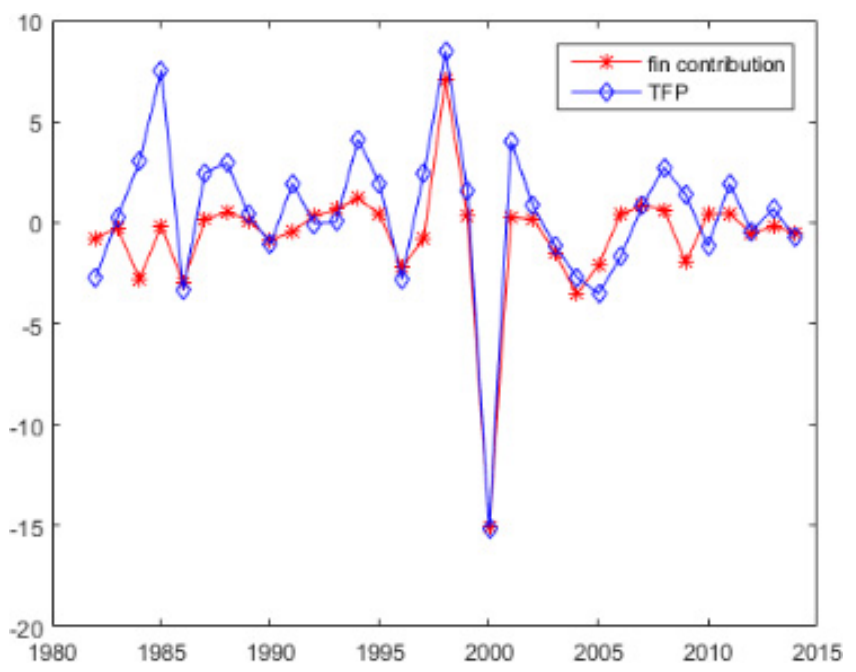

Figure 8. TFP with Contribution of Financial

between total factor productivity and the contribution of these factors. Figure 6 shows change paths of TFP and the contribution of openness. Figure 7 shows change paths of TFP and the contribution of industrial structure. Figure 8 shows change paths of TFP and the contribution of financial structure. Figure 9 shows change paths of TFP and government intervention.

From Figures 6 to 9, we find out that the TFP change shows a relatively consistent trend with the contribution of openness, industrial structure and financial structure. In Figure 6, the contribution of openness and TPF are in a rising state from 1982 to 1985 . They both suddenly fall sharply in 1986 and slip slowly three years later. TFP and the contribution of openness change perfectly in 1991-1996 and 2000-2014, and they have the same change

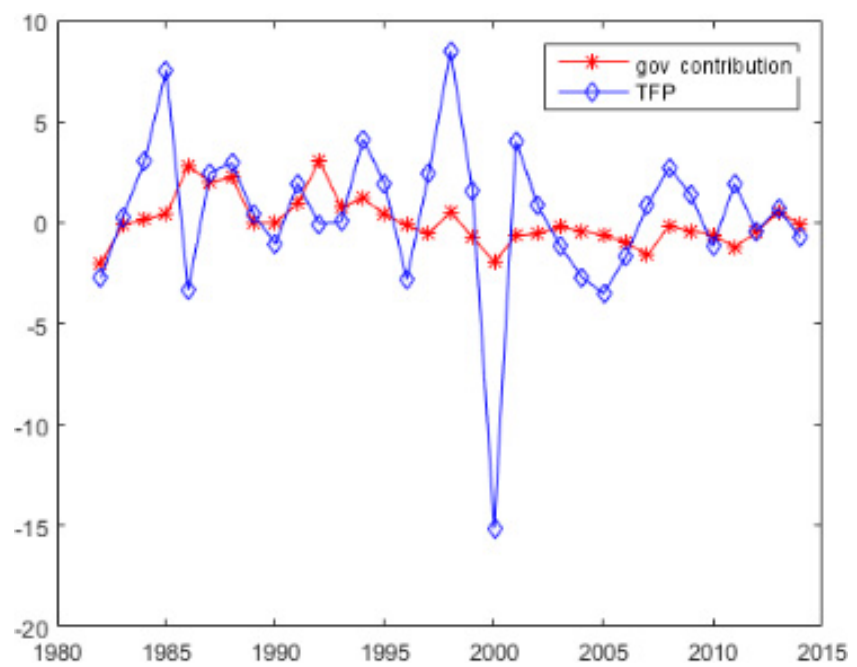

Figure 9. TFP with Contribution of Government 
trend. Figure 7 clearly shows that TFP and the contribution of industrial structure have a consistent change in 1982-2002, whereas they show an opposite change in following three years. From 2007, they maintain a consistent trend again. In Figure 8, in addition to 1984, TFP and the contribution of financial structure present the similar changes. Figures 6 to 8 confirm that openness, industrial structure and financial structure influence TFP, which will further influence economic development. In Figure 9, government contribution and TFP both increase in 1982-1985 and change differently in next two years. A consistent trend occurs in 1987-1991, whereas government contribution and TFP present a complex pattern of changes from 1992. Compared with the other three factors, contribution of government intervention to TFP change is weak, but there are no correlations.

\section{Conclusion and Policy Recommendations}

From the perspective of strong sustainability, this paper introduced environment (as a key natural capital) and energy consumption into a Cobb-Douglas production function and introduced government intervention, industrial structure, financial structure and degree of openness into the TFP accounting framework. We studied the long-run driving forces of economic growth in China and analyzed the sources of economic growth with the help of a VAR model in the short term. We found the following results:

(1) An inverted U-shaped relationship between the degree of openness and the industrial structure and their marginal growth effects, a U-shaped relationship between the financial structure and its marginal growth effect and a negative relationship between the government intervention and GDP growth are observed. According to the regression results, China's best ratio of tertiary industry and the secondary industry was about $86.64 \%$, and its appropriate degree of openness was about $42.64 \%$. At the "new normal" stage, industrial structure and openness deviating from the optimal allocation may be the reasons for the shift of China's economic growth.

(2) The main driving forces of China's economic growth (from the most to the least important) were physical capital, energy consumption, environmental pollution, human capital and TFP. China's economic growth was still "extensive" and unsustainable, let alone the strong sustainability.

(3) Total factor productivity was an important source of China's economic changes. The contribution of physical capital to economic growth was about $13.60 \%$. The contribution of human capital reached $6.17 \%$. The contribution of ecological loss to economic growth was smaller, about $2.26 \%$. The contribution of total factor productivity to economic growth was $37.15 \%$. The openness and the industrial structure were the main factors affecting total factor productivity.

More investment, more energy consumption, more environment pollution and high growth are the main characteristics of China's growth after its reform and opening-up. However, high capital accumulation has made it impossible for China to maintain a high growth rate in the future. The increasing energy consumption and the unreasonable energy structure that relies heavily on coal also bring traumas to China's strong sustainability. 
Achieving strong sustainable development is an inevitable choice for China's economy. According to the conclusions, we propose the following policy recommendations:

(1) Optimize the industrial structure and the degree of openness. It is essential for China to strengthen its openness; however, China should avoid heavily depending on imports and exports.

(2) China's future development should focus more on the reduction in consumption of key natural resources, such as energy and environment. At the same time, the stocks of resources should not be reduced and the environmental quality should be maintained. Otherwise, economic growth will not be sustainable.

(3) Steadily improve total factor productivity and reduce the undesirable impact of total factor productivity on economic growth. In particular, China should focus on resolving the potential adverse effect of industrial restructuring and the opening-up on total factor productivity.

\section{Acknowledgments}

The authors are supported by the National Social Sciences Fund (17BJL043). They gratefully acknowledge the help of Associate Professor Zeng Jinli at Department of Economics, National University of Singapore, for pointing out many problems and polishing the paper. They also want to acknowledge Associate Professor Liu Haoming at Department of Economics, National University of Singapore, for proposing some insightful suggestions on revision.

\section{Appendix A}

In order to obtain integrated environmental pollution index that can reflect the pollution levels, we ultimately select industrial wastewater, industrial waste gas and industrial solid waste as factors for environmental pollution index. Data are from "China Statistical Yearbook" and "China Environment Statistical Yearbook". Evaluation method of pollution index can be described as follows:

1. Data normalization

The step is to eliminate the difference of dimensions and dimensional units, which may bring incommensurability.

Assuming $\left\{x_{i j}\left(t_{k}\right)\right\}(i=1,2, \ldots, m ; j=1,2, \ldots, n ; k=1,2, \ldots, T)$ denote value of $j$ factor of sample $i$ at time $t$. We have

$$
x_{i j}^{\prime}\left(t_{k}\right)=\frac{x_{i j}\left(t_{k}\right)-\overline{x_{j}\left(t_{k}\right)}}{s_{j}\left(t_{k}\right)},
$$

where $x_{i j}^{\prime}\left(t_{k}\right)$ is the normalized value of $x_{i j}\left(t_{k}\right), \overline{x_{j}\left(t_{k}\right)}$ is the mean of $\left\{x_{j}\left(t_{k}\right)\right\}$ and $s_{j}\left(t_{k}\right)$ is the standard deviation of $\left\{x_{j}\left(t_{k}\right)\right\}$.

2. Calculate the real symmetric matrix $H_{k}$.

$$
H_{k}=X_{k} X_{k}^{T},
$$


where

$$
X_{k}=\left(\begin{array}{ccc}
x_{11}^{\prime}\left(t_{k}\right) & \cdots & x_{1 m}^{\prime}\left(t_{k}\right) \\
\vdots & \cdots & \vdots \\
x_{n 1}^{\prime}\left(t_{k}\right) & \cdots & x_{n m}^{\prime}\left(t_{k}\right)
\end{array}\right), \quad k=1,2, \ldots, T
$$

3. Solve the maximum eigenvalue and its corresponding standardized eigenvector $\lambda^{\prime}$ of real symmetric matrix $H$,

$$
H=H_{1}+H_{2}+\cdots+H_{k}(k=1,2, \ldots, T) .
$$

4. Normalize the standard standardized eigenvector $\lambda^{\prime}$ and obtain combination weight vector $\omega_{j}$.

5. Calculate environmental pollution index $P_{i}\left(t_{k}\right)$.

$$
P_{i}\left(t_{k}\right)=\sum_{j=1}^{n} \omega_{j} x_{i j}^{\prime}\left(t_{k}\right), \quad k=1,2, \ldots, T ; i=1,2, \ldots, m .
$$

\section{References}

Aghion, P et al., (1998). Endogenous Growth Theory. MIT Press, Massachusetts.

Aoki, M (2012). The five phases of economic development and institutional evolution in China, Japan, and Korea. Institutions and Comparative Economic Development, pp. 13-47. UK: Palgrave Macmillan.

Chang, Y-T et al., (2013). Environmental efficiency analysis of transportation system in China: A non-radial DEA approach. Energy Policy, 58, 277-283.

Chen, BQ, WY Fu and ZY Zhang (2007). Research on the influence of financial structure, government behavior, financial openness and economic growth in the process of Financial Marketization - Based on the experience of China (1978-2005). Journal of Financial Research, 10, $1-14$.

Chen, SY (2010). China's green industrial revolution: An interpretation based on the theory of environmental total factor productivity (1980-2008). Economic Research, 11, 21-34.

Chow, GC (1993). Capital formation and economic growth in China. The Quarterly Journal of Economics, 108(3), 809-842.

Chow, GC and KW Li (2002). China's economic growth: 1952-2010. Economic Development and Cultural Change, 51(1), 247-256.

Chung, W, YJ Wu and JD Fuller (1997). Dynamic energy and environment equilibrium model for the assessment of $\mathrm{CO}_{2}$ emission control in Canada and the USA. Energy Economics, 19(1), 103-124.

Dasgupta, P and PA David (1994). Toward a new economics of science. Research Policy, 23, 487-521.

Dasgupta, PS and GM Heal (1979). Economic Theory and Exhaustible Resources. Cambridge University Press, London.

Demirgüç-Kunt, A et al., (2011). Remittances and banking sector breadth and depth: Evidence from Mexico. Journal of Development Economics, 95(2), 229-241.

Ding, JH and KB Deng (2007). Government intervene natural resource and economy development based on regional panel data study of China. China Industrial Economy, 7, 56-64.

Field, BC (2005). Natural resource abundance and economic grouth. Social Science Electronic Publishing, 81(4), 496-502. 
Grimaud, A and L Rougé (2003). Non-renewable resources and growth with vertical innovations: Optimum, equilibrium and economic policies. Journal of Environmental Economics and Management, 45(2), 433-453.

$\mathrm{Hu}$, A et al., (2008). Provincial technical efficiency rankings for environmental considerations (1999-2005) Economics (Quarterly), 7(3), 933-960.

$\mathrm{Hu}, \mathrm{ZF}$ and MS Khan (1997). Why is China growing so fast? Staff Papers-International Monetary Fund, 103-131.

Jiang, Y (2015). Total factor productivity, pollution and 'green' economic growth in China. Journal of International Development, 27(4), 504-515.

Jin, T and XY Tao (2015). Analyzing and comparing periodic power of China's continuous economic growth. The Journal of Quantitative \& Technical Economics, 11, 74-89.

Krugman, P (1994). The myth of Asia's miracle. Foreign Affairs, 73, 62-78.

Krugman, P (2013). Hitting China's wall. The New York Times, 18.

Kuang, YF and DY Peng (2012). Analysis of environment production efficiency and environmental total factor productivity in China. Economic Research Journal, 7, 62-74.

Li, S and Z Huang (2015). Energy calculation of GDP contribution. Statistics and Decision, 1, 123-125.

Liu, BL and XL Yuan (2015). Comprehensive evaluation and convergence analysis of provincial environmental quality for China: An empirical analysis based on the years from 1996 to 2012. Journal of Xi'an Jiaotong University: Social Sciences Edition, 35(4), 32-39.

Liu, RX and TL An (2012). Trend and factor analysis of Chinese economic growth performance under restrictions of resource and environment - A research based on a new method of productivity index's construction and decomposition. Economic Research Journal, 11, 34-47.

Liu, XW (2011). The government regulation, mechanism reconstruction and resource city's getting rid of the dilemma. Reform, 3, 17-24.

Long, X, EY Naminse, J Du et al., (2015). Nonrenewable energy, renewable energy, carbon dioxide emissions and economic growth in China from 1952 to 2012. Renewable and Sustainable Energy Reviews, 52, 680-688.

Managi, S and S Kaneko (2006). Economic growth and the environment in China: An empirical analysis of productivity. International Journal of Global Environmental Issues, 6(1), 89-133.

Michio, W and K Tanaka (2007). Efficiency analysis of Chinese industry: A directional distance function approach. Energy Policy, 35(12), 6323-6331.

Nordhaus, WD, RN Stavins and ML Weitzman (1992). Lethal model 2: The limits to growth revisited. Brookings Papers on Economic Activity, 2, 1-59.

Pearce, DW, A Markandya and E Barbier (1989). Blueprint for a Green Economy. Earthscan, London.

People's Republic of China (2008). National Bureau of Statistics of China 2015. Beijing: China Statistics Press.

Romer, D (2001). Is growth exogenous? Taking Mankiw, Romer, and Weil seriously: Comment. NBER Macroeconomics Annual, 16, 62-70.

Sachs, JD and AM Warner (1995). Natural resource abundance and economic growth. No. w5398, National Bureau of Economic Research.

Sang, B and L Huang (2016). Government spending and economic volatility: An empirical analysis based on China's provincial panel data. South China Journal of Economics, 8, 60-74.

Smulders, S, L Bretschger and H Egli (2011). Economic growth and the diffusion of clean technologies: Explaining environmental Kuznets curves. Environmental and Resource Economics, 49(1), 79-99.

Solow, RM (1974). The economics of resources or the resources of economics. Classic Papers in Natural Resource Economics, pp. 257-276. UK: Palgrave Macmillan. 
Soytas, U and R Sari (2003). Energy consumption and GDP: Causality relationship in G-7 countries and emerging markets. Energy Economics, 25(1), 33-37.

Sweeney, J and EK Klavers (2007). Sustaining energy efficiency for a "greener" world. Hart Energy, 3, 18-29.

The World Bank (1997). Annual Report 1997. Washington, D.C.

Tyteca, D (1997). Linear programming models for the measurement of environmental performance of firms - Concepts and empirical results. Journal of Productivity Analysis, 8(2), 183-197.

Tzouvelekas, E, D Vouvaki and A Xepapadeas (2006). Total factor productivity growth and the environment: A case for green growth accounting. Beijer International Institute of Ecological Economics.

Wang, XL et al., (2009). Transformation of growth pattern and growth sustainability in China. Economic Research Journal, 1, 44-47.

$\mathrm{Wu}, \mathrm{ME}$, GP Zeng and YQ Cao (2015). Total factor productivity growth under the constraint of resource and environment based on capital service. China Population, Resources and Environment, 25(5), 83-91.

Xue, YJ and Y Liang (2011). Analysis of the source of economic growth based on SFA model - A comparison between Yunnan and the whole country. Contemporary Economics, 20, 93-95.

Young, A (2003). Gold into base metals: Productivity growth in the People's Republic of China during the reform period. Journal of Political Economy, 111(6), 1220-1261.

Yuan, XL and L Ban (2017). The propulsion, transformation and regional difference of China's economic growth - Based on nonparametric accounting framework decomposition of economic growth. Journal of Shaanxi Normal University (Philosophy and Social Sciences Edition), 3, 1-11.

Yuan, XL and ZD Li (2013). China's ecological environment dynamic change, regional differences and impact mechanism. Economic Science, 6, 59-76.

Zha, JP and ZY Li (2017). China's economic growth model and its influence factors under the restriction of recourses and environment. Journal of Shanxi University of Finance and Economics, 6, 1-14.

Zhang, J, GY Wu and JP Zhang (2003). The estimation of China's provincial capital stock: 19522000. Economic Research Journal, 10, 35-44.

Zhang, WG, YY Ren and XH An (2011). Local government investment, administrative monopoly and economic growth - Evidence from Chinese provincial panel data. Economic Research Journal, 8, 26-37.

Zhang, XR (2012). Strong Sustainable Development of Urban. Southeast University Press, Nanjing.

Zheng, LL and QG Zhu (2013). Re-estimation of total factor productivity in China accounting for the energy and environment factors. Statistical Research, 30(7), 9-17.

Zheng, W and F Zhou (2015). Fluctuation track, dynamic characteristics and mechanism of economic stability and growth in China. Journal of Guizhou University of Finance and Economics, $5,14-25$. 